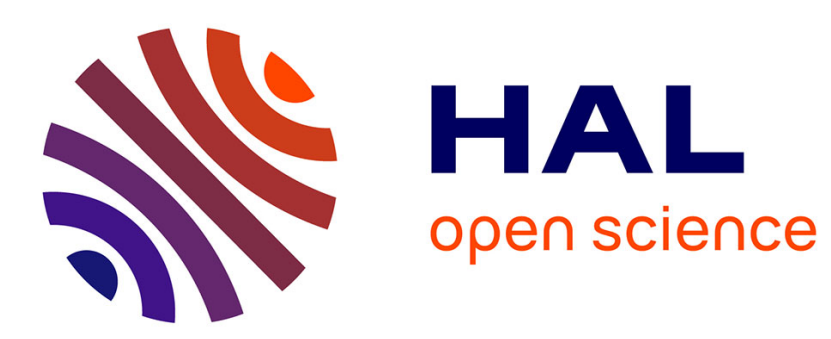

\title{
Back-arc strain in subduction zones: Statistical observations versus numerical modeling
}

Diane Arcay, Serge Lallemand, M. P. Doin

\section{To cite this version:}

Diane Arcay, Serge Lallemand, M. P. Doin. Back-arc strain in subduction zones: Statistical observations versus numerical modeling. Geochemistry, Geophysics, Geosystems, 2008, 9, pp.Q05015. 10.1029/2007GC001875 . hal-00412328

\section{HAL Id: hal-00412328 \\ https://hal.science/hal-00412328}

Submitted on 16 Dec 2015

HAL is a multi-disciplinary open access archive for the deposit and dissemination of scientific research documents, whether they are published or not. The documents may come from teaching and research institutions in France or abroad, or from public or private research centers.
L'archive ouverte pluridisciplinaire HAL, est destinée au dépôt et à la diffusion de documents scientifiques de niveau recherche, publiés ou non, émanant des établissements d'enseignement et de recherche français ou étrangers, des laboratoires publics ou privés. 


\title{
Back-arc strain in subduction zones: Statistical observations versus numerical modeling
}

\author{
D. Arcay \\ Institute of Geophysics, ETH Zurich, Schafmattst. 30, HPP-L10, CH-8093 Zurich, Switzerland \\ (diane.arcay@erdw.ethz.ch)
}

\section{S. Lallemand}

Géosciences Montpellier Laboratory, Université Montpellier 2, CNRS, CC60, Place E. Bataillon, F-34095 Montpellier CEDEX 05, France

\section{M.-P. Doin}

Ecole Normale Supérieure, Laboratoire de Géologie, UMR 8538, 24 rue Lhomond, F-75231 Paris CEDEX 05, France

[1] Recent statistical analysis by Lallemand et al. (2008) of subduction zone parameters revealed that the back-arc deformation mode depends on the combination between the subducting $\left(v_{\text {sub }}\right)$ and upper $\left(v_{u p}\right)$ plate velocities. No significant strain is recorded in the arc area if plate kinematics verifies $v_{u p}=0.5 v_{s u b}-$ $2.3(\mathrm{~cm} / \mathrm{a})$ in the HS3 reference frame. Arc spreading (shortening) occurs if $v_{u p}$ is greater (lower) than the preceding relationship. We test this statistical law with numerical models of subduction, by applying constant plate velocities far away from the subduction zone. The subducting lithosphere is free to deform at all depths. We quantify the force applied on the two converging plates to sustain constant surface velocities. The simulated rheology combined viscous (non-Newtonian) and brittle behaviors, and depends on water content. The influence of subduction rate $v_{s}$ is first studied for a fixed upper plate. After $950 \mathrm{~km}$ of convergence (steady state slab pull), the transition from extensional to compressive stresses in the upper plate occurs for $v_{s} \sim 1.4 \mathrm{~cm} / \mathrm{a}$. The effect of upper plate velocity is then tested at constant subduction rate. Upper plate retreat (advance) with respect to the trench increases extension (compression) in the arc lithosphere and increases (decreases) the subducting plate dip. Our modeling confirms the statistical kinematic relationship between $v_{s u b}$ and $v_{u p}$ that describes the transition from extensional to compressive stresses in the arc lithosphere, even if the modeled law is shifted toward higher rates of upper plate retreat, using our set of physical parameters (e.g., $100 \mathrm{~km}$ thick subducting oceanic plate) and short-term simulations. Our results make valid the choice of the HS3 reference frame for assessing plate velocity influence on arc tectonic regime. The subduction model suggests that friction along the interplate contact and the mantle Stokes reaction could be the two main forces competing against slab pull for upper mantle subductions. Besides, our simulations show that the arc deformation mode is strongly time dependent.

Components: 5018 words, 16 figures, 5 tables.

Keywords: subduction dynamics; back-arc strain; subduction force balance; plate kinematics; friction; numerical modeling.

Index Terms: 8170 Tectonophysics: Subduction zone processes (1031, 3060, 3613, 8413); 8163 Tectonophysics: Rheology and friction of fault zones (8034); 8155 Tectonophysics: Plate motions: general (3040).

Received 28 October 2007; Revised 12 February 2008; Accepted 3 March 2008; Published 21 May 2008. 
Arcay, D., S. Lallemand, and M.-P. Doin (2008), Back-arc strain in subduction zones: Statistical observations versus numerical modeling, Geochem. Geophys. Geosyst., 9, Q05015, doi:10.1029/2007GC001875.

\section{Introduction}

[2] In subduction zones, arc-back-arc stress results from the balance of forces acting on the two converging plates and on their coupling with the convecting mantle. Various approaches have been proposed to account for the resultant stress. Laboratory experiments showed that the positive (or negative) buoyancy of the sinking plate generates arc compression (or extension) associated with a positive (or negative) free-air anomaly in the forearc region [Shemenda, 1994]. Later, friction along the contact area between the plates was shown to always rise compressive stresses in the upper plate [Chemenda et al., 2000]. Numerical modeling, focused on the converging lithosphere coupling [e.g., Hassani et al., 1997], confirmed Shemenda's [1994] results, while other authors investigated the energy dissipated in the subducting lithosphere [e.g., Conrad and Hager, 1999; Regenauer-Lieb and Yuen, 1998], including in some cases 3D subduction-induced mantle flows [e.g., Stegman et al., 2006; Funiciello et al., 2006; Piromallo et al., 2006]. The great majority of these models was performed either without upper plate, with a fixed trench, or with trench rollback with respect to a passive mantle. Experiments with Newtonian fluids [e.g., Funiciello et al., 2003a, 2004; Enns et al., 2005] brought to the fore 3 modes of subduction: forward, backward, or alternative trench migration, depending on plate thickness, width, strength, mantle viscosity, and density. A balance between driving and resisting forces, such as slab pull, bending resistance, or viscous drag, was proposed to explain the three subduction modes [Bellahsen et al., 2005; Faccenna et al., 2007]. [Carlson and Melia, 1984] emphasized from the early eighties that some current trenches may migrate arcward. More recently, Heuret and Lallemand [2005], on the basis of an updated database of modern subduction zones, showed that half of the trenches are prograding (arcward migration) if their motion is estimated in the HS3 Pacific hot spots reference frame [Gripp and Gordon, 2002]. It became essential to test how trench migration (free or forced) interacted with subduction dynamics. More precisely, Heuret et al. [2007] investigated how converging plate kinematics affected back-arc stress using laboratory models and confirmed the observation that com- pression or extension in the overriding plate result from the combination of plate velocities (Figure 1). Lallemand et al. [2008] further defined "neutral arcs" characterized by the absence of significant strain, meaning places where the balance of subduction forces (slab pull, plate bending, plate anchoring) sets the arc almost stress free. They show that "neutral" subduction zones satisfy the kinematic relation between absolute motions of the upper $\left(v_{u p}\right)$ and subducting plate $\left(v_{\text {sub }}\right)$ velocities: $v_{\text {sub }}-2 v_{u p}=$ $4.6 \mathrm{~cm} / \mathrm{a}$, where $v_{u p}=v_{t}$ (trench velocity), or, expressed as a function of upper plate velocity and convergence rate, $v_{c}\left(v_{c}=v_{s u b}-v_{u p}\right.$, Figure 2):

$$
v_{t}=v_{u p}=v_{c}-4.6
$$

The coefficients appearing in equation (1) depend on the reference frame used to estimate major plate velocities [Lallemand et al., 2008]. For example, the use of the NNR or SB04 reference frames [DeMets, 2001; Gripp and Gordon, 2002; Steinberger et al., 2004] leads to an influence of upper plate velocity in relation to $v_{c}$ stronger than expressed by equation (1). In any cases, deformation is favored when the velocity combination deviates from this kinematic relation. The limitations of such statistical approaches of subduction zone parameters are the heterogeneity of subduction stages (short slabs versus lower mantle penetrating slabs, young versus old subduction zones...) and the fact that we have only access to the present-day situation. In this paper, we test the kinematic relationship (1) describing the arc deformation mode with numerical simulations that model the mantlelithosphere coupling, the mantle wedge hydration and the global dynamics of the system by running long-term experiments, i.e., typically $40 \mathrm{Ma}$ of convergence.

[3] The model mimics plate tectonics by applying plate velocities at the surface. The upper plate velocity is considered as a boundary condition, as it assumed to be independent of the subduction process. On the contrary, the subducting lithosphere velocity at the surface is likely to be regulated by the subduction process it-self. However, the subducting plate velocity cannot be accurately controlled in fully dynamical models of subduction [e.g., Funiciello et al., 2003b; Capitanio et al., 2007]. We thus choose to set 


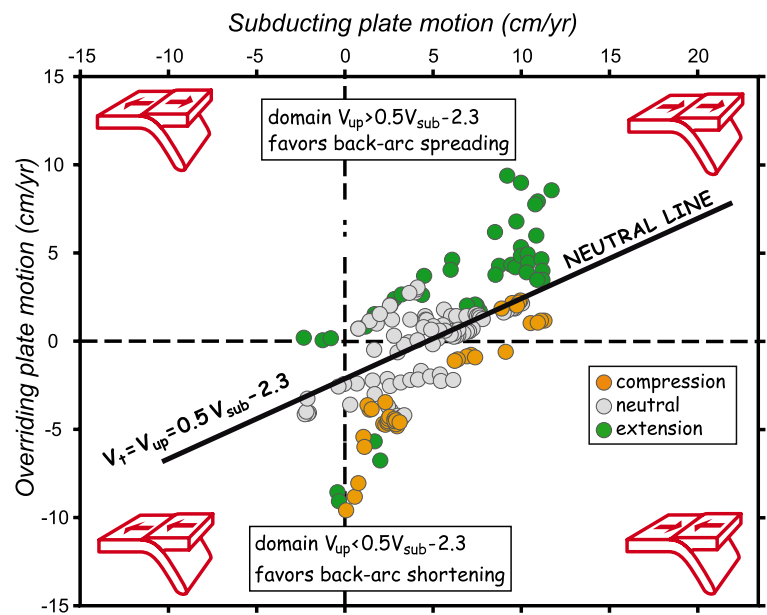

Figure 1. Overriding plate velocity, $v_{u p}$, versus subducting plate velocity, $v_{\text {sub }}$ (components normal to the trench), for 166 transects across modern subductions as a function of the back-arc strain, adapted from Lallemand et al. [2008]. The "neutral line," $v_{u p}=0.5$ $v_{\text {sub }}-2.3$, is the regression line among the transects for which arc-back-arc strain is not significant. If no strain occurs within the overriding plate $\left(v_{d}=0\right)$, the trench velocity equals the upper plate velocity: $v_{t}=v_{u p}$.

$v_{s u b}$ as a boundary condition. Kinematic boundary conditions are applied far away from the trench, which enables a large degree of freedom, including trench velocity, rate of arc deformation, and subducting plate dip at all depths. The work supplied by boundary conditions is quantified to evaluate how surface kinematics influences backarc stress. Although the modeled rheology, brittle or non-Newtonian, should be an acceptable proxy of mantle and crust rheologies, we do not model, for instance, rock elasticity [Regenauer-Lieb and Yuen, 1998; Levitt and Sandwell, 1995; Hall and Gurnis, 2003; Billen and Gurnis, 2005]. Therefore, our model may not simulate the different subduction forces with the exact proportions encountered in nature. Our purpose is rather to study the respective influence of the two converging plate velocities, while other subduction parameters are kept constant (e.g., lithosphere structures and rheological parameters). We simulate water transfers associated with slab dehydration, and a water weakening effect for hydrated rocks leading to the thermal thinning of the metasomatized arc lithosphere, as suggested by several studies [Honda and Yoshida, 2005; Garrido et al., 2006, 2007; Currie and Hyndman, 2006; Garzione et al., 2005; Dhuime et al., 2007]. The thinned arc weakness is here used as a strain sensor.

\section{Numerical Setup}

[4] Simulations are performed with a thermochemical code of convection [Christensen, 1992], solving equations of momentum, energy, and mass conservation. Rocks are assumed to be incompressible, except for the thermal buoyancy term in the momentum equation, and the adiabatic heating term in the energy equation (extended Boussineq approximation). A uniform heat production, as well as shear heating (i.e., viscous and frictional dissipations), are included in the heat conservation equation. The simulation box, $2220 \mathrm{~km}$ wide and $555 \mathrm{~km}$ high (Figure 3), is composed by two kinds of rock, oceanic crust and mantle, with specific density and rheology. The composition field is tracked by active tracers, that are advected with the velocity field [van Keken et al., 1997]. We briefly describe, first, the model boundary conditions and converging plate structures at simulation start. The modeling of water transfers associated with metamorphic reactions is presented in section 2.2. The water weakening model implemented for

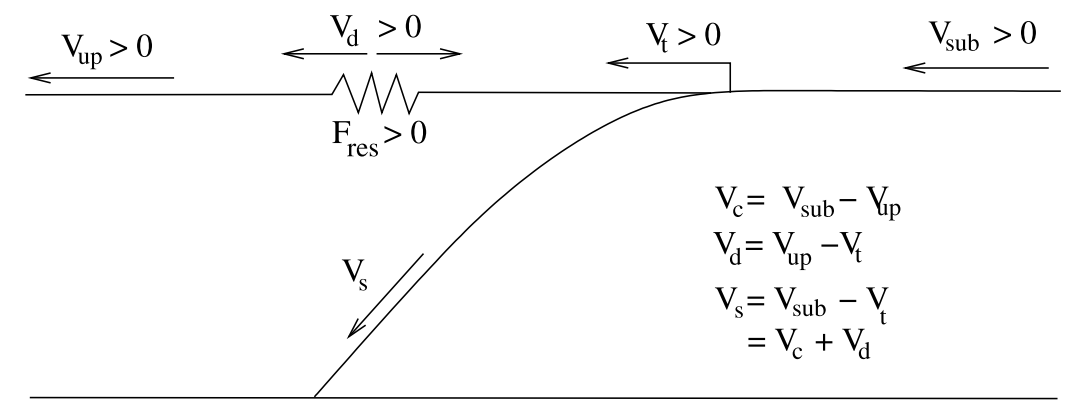

Figure 2. Sign convention for velocities and resulting force. The hot and weak arc lithosphere is depicted by a spring deforming as a strain sensor. Note that deformation velocity in the arc lithosphere $\left(v_{d}\right)$ and trench velocity $\left(v_{t}\right)$ simulated at the surface are only horizontal, since the model surface is not free. 

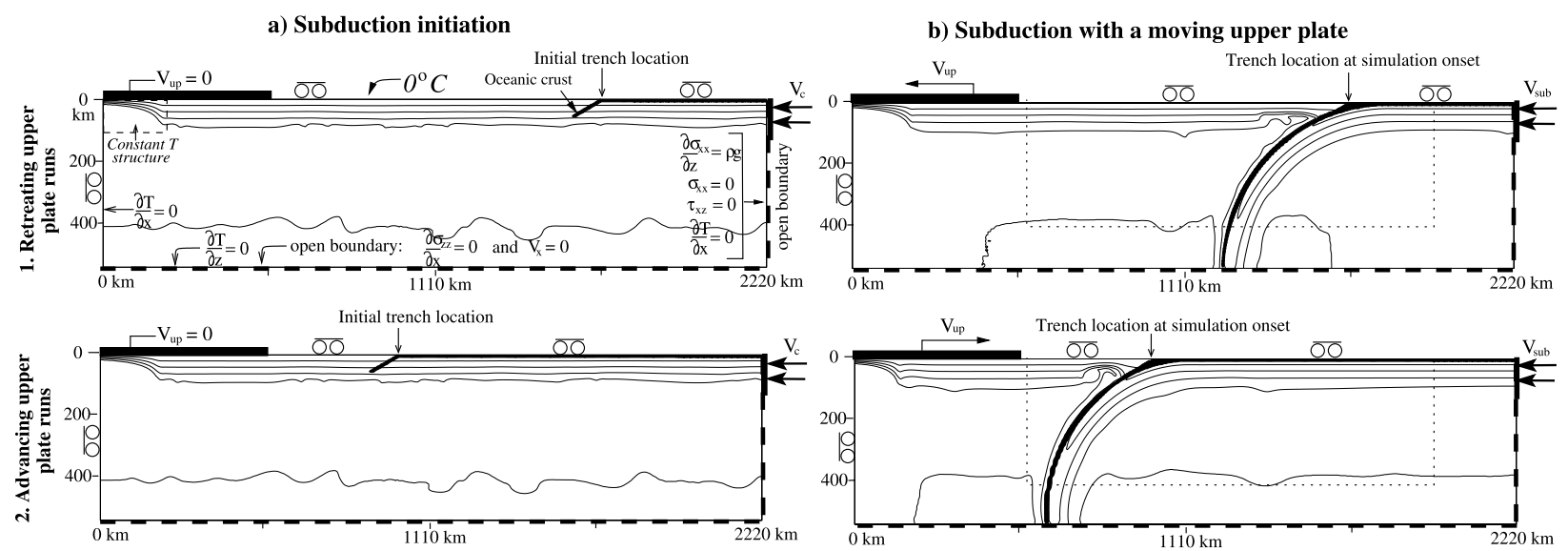

Figure 3. Boundary conditions and initial thermal and compositional fields within the simulation box, to simulate (a) subduction development from initiation to slab steady state and (b) the influence of surface kinematics, once the subducted slab length exceeds $\sim 950 \mathrm{~km}$. The thick black line at the box surface on the left side represents the domain over which upper plate velocity is imposed. Isotherms (black lines) are depicted every $300^{\circ} \mathrm{C}$. The black filled outline delimits the oceanic crust. In the top left corner of the simulation box, the thermal structure of a pseudoridge inside the dashed line area is sustained through time. The dotted box represents the model domain depicted in Figures 8,10 , and 12.

hydrated mantle rocks is described in the rheology section.

\subsection{Subduction Geometry and Boundary Conditions}

[5] We study separately the influence of subduction velocity and upper plate motion. Plate convergence is thus simulated in two steps. During step 1, subduction is computed from initiation to slab steady state for a motionless upper plate (simulations S1-S13, Table 2, and Figure 3a). The upper plate motion is tested in a second step: Simulations start from a stable state of subduction (end of step 1 ), and are carried on with an upper plate velocity different from zero, but keeping the convergence rate constant (simulations S14-S28, Table 2, and Figure $3 b$ ). The trench initial location as well as plate velocities are chosen to be compatible in both setups (section 2.1.3).

\subsubsection{Subduction Initiation Model (Step 1)}

[6] Subduction is modeled by applying a constant subduction rate, and, on the other hand, by maintaining a low strength at the interplate boundary to localize deformation. The subduction velocity is imposed along the right vertical section of the incoming plate, whereas the remaining section of the box open right side is stress free (Figure 3a). A $7 \mathrm{~km}$ thick layer of weak oceanic crust covers the subducting plate. Both the thermal structure and the crustal layer of the incoming plate are continuously regenerated as the plate enters the simulation box across the right side. Subduction is initiated by imposing a weak dipping plate made of oceanic crust forming the interplate interface until $55 \mathrm{~km}$ depth, with a $30^{\circ}$ dip angle (Figure 3). The oceanic crust strength is assumed to be very low with respect to the mantle stiffness (section 2.3). At convergence start, deformation localizes along the weak dipping plane and favors plate bending. While subduction proceeds, the subducting crust layer continuously fills the subduction plane, which sustains deformation localization. We choose not to vary the initial dip angle, even though it may affect the subducting slab shape [Arcay et al., 2006]. The overriding lithosphere is made of peridotite only. Along the open bottom surface, a zero horizontal velocity is imposed. This condition will increase the subducting slab anchoring in the stiff deep mantle, competing against the hinge migration. Convergence is performed for a fixed upper plate (see below) until the thermal structure of the subducting lithosphere is steady state for the applied convergence rate, $v_{c}$, which is verified for slab lengths reaching $\sim 950 \mathrm{~km}$. At subduction initiation, both converging plates are $100 \mathrm{~km}$ thick. Their initial thermal state results from a thermal equilibrium with the underlying convecting mantle (whose thermal structure includes the adiabatic gradient), performed without plate tectonics in a presubduction simulation. The subducting lithosphere is thus 
assumed to be $\sim 100$ Ma old. The modeled thermal properties are classical values [e.g., Ricard, 2007].

\subsubsection{Upper Plate Motion Modeling (Step 2)}

[7] The overriding plate velocity is imposed on top of the plate left part, on a $555 \mathrm{~km}$ length from the box left side (Figure 3), until $\sim 16 \mathrm{~km}$ depth. Slip is free along the remaining surface. A pseudoridge is imposed at the upper plate extremity, and simulates the plate conductive cooling from $0 \mathrm{Ma}$ to $100 \mathrm{Ma}$ on a $200 \mathrm{~km}$ width (Figure 3). Both the thermal structure and the width of the pseudoridge are constantly sustained as a boundary condition. As the box left side is closed, this pseudoridge is used to either absorb the upper plate shrinking caused by the plate retreat from the subduction zone (Figure 3, panel 1) or to allow for the upper plate lengthening required to accommodate trenchward advance. Other mechanical and thermal boundary conditions are displayed in Figure 3.

\subsubsection{Trench Location at Simulation Start and Choice of Plate Velocities}

[8] The trench position is here defined by the location where the upper surface of the interplate crust layer intersects the surface. During step 2 experiments, the trench is expected to move in the same direction as the upper plate if the arc-backarc deformation is weak. The trench location at step 1 initiation (Figure 3a) is thus chosen as a function of the next step 2 experiment: For upper plate retreat experiments, the trench is located $1665 \mathrm{~km}$ away from the left-hand box side (Figure 3, top row 1), while, for upper plate advance simulations, it is set to $1000 \mathrm{~km}$ (Figure 3, bottom row 2). Note that after subduction initiation, the trench may freely move in a dynamically selfconsistent way. However, the trench location remains more or less constant during the whole step 1 , as the upper plate velocity is set to zero.

[9] We choose to keep constant the subducting slab thermal structure when the upper plate velocity is imposed, in order to maintain the same slab strength in both setups. Consequently, the convergence rate must be identical before and once upper plate velocity is imposed. The kinematic boundary conditions from step 1 to step 2 experiment verify:

$$
v_{\text {sub }}^{\text {step } 2}=v_{c}^{\text {step } 1}+v_{u p}^{\text {step } 2}
$$

where $v_{\text {sub }}^{\text {step }} 2$ is the subducting plate velocity (positive trenchward), $v_{u p}^{\text {step } 2}$ is the upper plate velocity (negative trenchward), and $v_{c}^{\text {step }} 1$ is the convergence rate before upper plate motion initiation (Figure 2).

\subsection{Initial Hydration State and Water Migration Model}

[10] Water transfers are computed as a function of dehydration and hydration metamorphic reactions, according to hydrated mineral stability domains. We use two phase diagrams, one for the gabbroic crust [Bousquet et al., 1997] and the other for peridotite [Schmidt and Poli, 1998] giving water contents at saturation. Before subduction, the oceanic crust water content is set to $2.97 \mathrm{wt} \%$, which corresponds before burying to water saturation of gabbro in the greenschist facies. A $10 \mathrm{~km}$ thick layer of mantle underlying the oceanic crust is assumed to be fully serpentinized and contains $6.5 \mathrm{wt} \%$ of water. This simple hydration state before subduction models the shallow plate hydroalteration near the ridge, and deep hydration along normal faults at outer bulge [Ranero et al., 2003].

[11] In asthenospheric pressure and temperature $(P-T)$ conditions, nominally hydrated minerals are not stable. We include in this domain the water amount dissolved by peridotite, by computing water solubilities at $1000^{\circ} \mathrm{C}$ in olivine, pyrope, and pyroxene [Kohlstedt et al., 1996; Lu and Keppler, 1997; Rauch and Keppler, 2002]. The modeled mantle solubility increases with pressure from $\sim 390 \mathrm{ppm}$ at $70 \mathrm{~km}$ depth to $\sim 0.145 \mathrm{wt} \%$ at $190 \mathrm{~km}$ depth [Arcay et al., 2005]. In the wet partial melting domain, the mantle water content is assumed to decrease linearly from the saturation value below the wet solidus to zero at the dry solidus [Mei et al., 2002]. We neglect the water left in the solid residue after magma migration, as partition coefficients are very low [Asimow et al., 2004].

[12] We compute water transfers at each time step, for every tracer located inside the subduction zone. The maximum water content depends on local $P-T$ and composition (crust/mantle) conditions: It corresponds to the saturation value indicated by phase diagrams. If a tracer crosses a dehydration reaction between two time iterations, the water in excess is released and migrates vertically instantaneously. This "free" water is absorbed by the nearest under-saturated tracer until saturation. Latent heat 
Table 1. Thermomechanical Parameter Names and Values

\begin{tabular}{|c|c|c|}
\hline Parameter Name & Symbol & Value \\
\hline Box height & $H_{0}$ & $555 \mathrm{~km}$ \\
\hline Bottom temperature & $T_{b}$ & $1888 \mathrm{~K}$ \\
\hline Surface temperature & $T_{S}$ & $273 \mathrm{~K}$ \\
\hline Mantle density & $\rho_{m}$ & $3300 \mathrm{~kg} \cdot \mathrm{m}^{-3}$ \\
\hline Crustal density & $\rho_{c}$ & $2920 \mathrm{~kg} \cdot \mathrm{m}^{-3}$ \\
\hline $\begin{array}{l}\text { Mantle radiogenic } \\
\text { heat production }\end{array}$ & $A$ & $9.20 \times 10^{-8}$ W.m ${ }^{-3}$ \\
\hline $\begin{array}{l}\text { Adiabatic gradient } \\
\text { Thermal diffusivity }\end{array}$ & $\begin{array}{c}\left(\frac{\partial T}{\partial z}\right)_{a d i a b} \\
\kappa\end{array}$ & $\begin{array}{c}0.445 \mathrm{~K} \cdot \mathrm{km}^{-1} \\
0.8 \times 10^{-6} \mathrm{~m}^{2} \cdot \mathrm{s}^{-1}\end{array}$ \\
\hline $\begin{array}{l}\text { Thermal expansion } \\
\text { coefficient }\end{array}$ & $\alpha$ & $3.5 \times 10^{-5} \mathrm{~K}^{-1}$ \\
\hline Heat capacity & $C_{p}$ & $0.971 \times 10^{3} \mathrm{~J} .(\mathrm{K} . \mathrm{kg})^{-}$ \\
\hline Gravity acceleration & $g$ & $9.81 \mathrm{~m} \cdot \mathrm{s}^{-2}$ \\
\hline Oceanic crust thickness & $\stackrel{\circ}{H}_{c}$ & $7 \mathrm{~km}$ \\
\hline $\begin{array}{l}\text { Preexponential constant, } \\
\text { "dry" viscous } \\
\text { rheology }\end{array}$ & $A_{0}^{d r y}$ & $53280 \mathrm{~Pa} \cdot \mathrm{s}^{\frac{1}{3}}$ \\
\hline $\begin{array}{l}\text { Activation energy in } \\
\text { the mantle }\end{array}$ & $E_{a}{ }^{m}$ & $395 \mathrm{~kJ} \cdot \mathrm{mol}^{-1}$ \\
\hline $\begin{array}{l}\text { Activation energy in } \\
\text { the crust }\end{array}$ & $E_{a}{ }^{c}$ & $285 \mathrm{~kJ}^{\mathrm{mol}}{ }^{-1}$ \\
\hline Activation volume & $V_{a}$ & $2.34 \times 10^{-5} \mathrm{~m}^{3} \cdot \mathrm{mol}^{-1}$ \\
\hline Cohesive strength & $\tau_{0}$ & $1 \mathrm{MPa}$ \\
\hline $\begin{array}{l}\text { Stress exponent in the } \\
\text { viscous rheology }\end{array}$ & $n$ & 3 \\
\hline $\begin{array}{l}\text { Stress exponent in the } \\
\text { brittle rheology }\end{array}$ & $n_{p}$ & 30 \\
\hline Reference strain rate & $\dot{\varepsilon}_{r e f}$ & $10^{-14} \mathrm{~s}^{-1}$ \\
\hline $\begin{array}{l}\text { Yield stress increase } \\
\text { with depth (crust) }\end{array}$ & $\gamma_{c}$ & 0.06 \\
\hline $\begin{array}{l}\text { Yield stress increase } \\
\text { with depth (mantle) }\end{array}$ & $\gamma_{m}$ & 1.5 \\
\hline
\end{tabular}

of metamorphic reactions is not modeled. If the migrating water reaches $11 \mathrm{~km}$ depth without being absorbed, it is extracted from the simulation box.

\subsection{Rheology}

\subsubsection{Pseudobrittle and Viscous Behaviors}

[13] The modeled rheology depends on temperature, $T$, pressure, $P$, strain rate, $\dot{\varepsilon}$, composition, $C$ (crust or mantle), and water content, $\left[\mathrm{OH}^{-}\right]$. We combine a pseudobrittle behavior and a viscous rheology, through an effective viscosity, $\nu_{\text {eff }}$, given by: $\tau=\nu_{\text {eff }} \dot{\varepsilon}$, where $\tau$ and $\dot{\varepsilon}$ are the second invariants of the stress and strain rate tensors. The effective viscosity is the inverse average between a brittle term, $\nu_{b}$, and the non-Newtonian viscous strength, $\nu_{v}$, assuming that the total deformation rate is the sum of brittle deformation and viscous deformation: $\nu_{\text {eff }}^{-1}=\nu_{b}^{-1}+\nu_{v}^{-1}$.
[14] The pseudobrittle behavior models a yield stress, $\tau_{y}$, increasing with depth, $z$ :

$$
\tau_{y}=\tau_{0}+\gamma_{\chi} \rho g z
$$

where $\tau_{0}$ is the cohesive strength at the surface, $\gamma$ is the yield stress increase with depth depending on composition ( $\chi$ refers either to crust, $c$, or mantle, $m$, Table 1 ), and $\rho$ is the density. The effective viscosity in the brittle domain is: $\nu_{b}=\tau_{y} \frac{\dot{\varepsilon}^{\frac{1}{n_{p}}-1}}{\dot{\varepsilon}_{r e f}^{\frac{1}{p_{p}}}}$ where $\dot{\varepsilon}_{r e f}$ is a reference strain rate and $n_{p}$ is a large stress exponent (Table 1). This relationship leads to very high strain rates as soon as stress exceeds the yield stress. In the ductile domain, the non-Newtonian viscosity writes as:

$$
\nu_{v}=A_{0}\left(\left[O H^{-}\right]\right) \exp \left(\frac{E_{a}(C)+V_{a} \rho g z}{n R T}\right) \dot{\varepsilon}^{\frac{1}{n}-1}
$$

where $A_{0}$ is a coefficient depending on water content (see section 2.3.2), $E_{a}$ is the activation energy depending on composition, $V_{a}$ is the activation volume, $n$ is an exponent greater than 1 , and $R$ is the gas constant (Table 1). The crust thermomechanical parameters simulate an intermediate behavior between the wet diorite and the dry diabase rheologies [Kirby, 1983; Ranalli, 1995]. The modeled mantle behavior is very close to the wet dunite rheology [Chopra and Paterson, 1984]. The yield stress increase with depth chosen for the mantle (Table 1) corresponds to a classical friction coefficient $\left(f_{s}^{m}=0.6\right.$ [Byerlee, 1978; Turcotte and Schubert, 1982]). We model a low yield stress increase with depth for the crust $\left(\gamma_{c}=0.06\right.$, Table 1$)$, in agreement with the values inferred for the interplate plane of several subduction zones (encompassed between 0.02 and 0.09 for the Cascadia, NE and SW Japan subduction zones [Wang and Suyehiro, 1999; Wang and He, 1999; von Herzen et al., 2001; Lamb, 2006]). Note that the crust yield stress increase with depth, $\gamma_{c}$, and the crust activation energy, $E_{a}^{c}$, are low with respect to their mantle equivalents (Table 1). As a consequence, the modeled crust is weaker than the mantle in the brittle as well as in the viscous domains.

\subsubsection{Water Weakening Effect}

[15] We model the water weakening effect by an ad hoc viscosity decrease in the non-Newtonian domain by decreasing the preexponential constant, $A_{0}$, in equation (4), as a function of water content, $\left[\mathrm{OH}^{-}\right]$:

$$
A_{0}\left(\left[O H^{-}\right]\right)=A_{0}^{d r y}\left(\left[1-\frac{1}{f_{\nu}}\right] \exp \left(-\frac{\left[O H^{-}\right]}{\left[O H^{-}\right]_{0}}\right)+\frac{1}{f_{\nu}}\right)
$$


Table 2. Long-Term Subduction Simulations

\begin{tabular}{|c|c|c|c|c|c|c|c|c|c|}
\hline Simulation & $\begin{array}{c}\text { Conv. } \\
\text { Rate, } v_{c}, \\
\mathrm{~cm} / \mathrm{a}\end{array}$ & $\begin{array}{l}\text { Upper } \\
\text { Plate } \\
\text { Velocity, } \\
\mathrm{cm} / \mathrm{a}\end{array}$ & $\begin{array}{l}\text { Subducting } \\
\text { Plate } \\
\text { Velocity, } \\
\text { cm/a }\end{array}$ & $\begin{array}{c}\text { Initial } \\
\text { Trench } \\
\text { Location, }^{\mathrm{a}} \\
\mathrm{km}\end{array}$ & $\begin{array}{l}\text { Simulation } \\
\text { Used for } \\
\text { Initiation }\end{array}$ & $\begin{array}{l}\text { Time at } \\
\text { Model } \\
\text { Start, } \\
\mathrm{Ma}\end{array}$ & $\begin{array}{c}\text { Final Time } \\
\text { Since } \\
\text { Subduction } \\
\text { Initiation } A_{S}, \mathrm{Ma}\end{array}$ & $\begin{array}{l}\quad F_{\text {res }} \text { at } \\
\text { Run Start } \\
\left(10^{12} \mathrm{~N} / \mathrm{m}\right)\end{array}$ & $\begin{array}{l}F_{r e s} \text { at } \\
\text { Time } A_{S} \\
\left(10^{12} \mathrm{~N} / \mathrm{m}\right)\end{array}$ \\
\hline S1 & 5 & 0 & 5 & 1388 & - & 0 & 55 & - & -6.7 \\
\hline S2 & 1 & 0 & 1 & 1665 & - & 0 & 76 & - & 3.5 \\
\hline S3 & 1.2 & 0 & 1.2 & 1665 & - & 0 & 71 & - & 1.3 \\
\hline $\mathrm{S} 3 \mathrm{~b}$ & 1.4 & 0 & 1.4 & 1665 & - & 0 & 67 & - & 0.8 \\
\hline S4 & 1.6 & 0 & 1.6 & 1665 & - & 0 & 77 & - & -2.3 \\
\hline S5 & 2.5 & 0 & 2.5 & 1000 & - & 0 & 40 & - & -5.4 \\
\hline S6 & 3 & 0 & 3 & 1665 & - & 0 & 43 & - & -2.7 \\
\hline S6b & 4 & 0 & 4 & 1665 & - & 0 & 40 & - & -0.7 \\
\hline S7 & 5 & 0 & 5 & 1000 & - & 0 & 19 & - & -7.7 \\
\hline S8 & 6 & 0 & 6 & 1665 & - & 0 & 16 & - & -5.5 \\
\hline S9 & 7 & 0 & 7 & 1665 & - & 0 & 21.5 & - & -2 \\
\hline S10 & 7.5 & 0 & 7.5 & 1665 & - & 0 & 13 & - & -4.7 \\
\hline S11 & 8 & 0 & 8 & 1665 & - & 0 & 13.5 & - & -4.3 \\
\hline $\mathrm{S} 12$ & 9 & 0 & 9 & 1665 & - & 0 & 11 & - & -4.6 \\
\hline $\mathrm{S} 13$ & 11 & 0 & 11 & 1665 & - & 0 & 13 & - & -2.0 \\
\hline S14 & 1 & 1 & 2 & 1665 & $\mathrm{~S} 2$ & 76 & 88 & 4.8 & $\sim 0$ \\
\hline S15 & 2.5 & -2.5 & 0 & 1000 & S5 & 40 & 70 & -6.6 & -23 \\
\hline S16 & 3 & 1 & 4 & 1665 & S6 & 30 & 35.3 & -2.0 & -2.9 \\
\hline S17 & 3 & 2 & 5 & 1665 & S6 & 30 & 35 & -0.8 & -0.2 \\
\hline S18 & 3 & 3 & 6 & 1665 & S6 & 30 & 39 & 0.7 & -0.5 \\
\hline S19 & 3 & 4 & 7 & 1665 & S6 & 30 & 35.3 & 2.6 & 1.6 \\
\hline $\mathrm{S} 20$ & 5 & 6.3 & 1.3 & 1388 & S7 & 19 & 33.3 & -4.3 & -2.9 \\
\hline $\mathrm{S} 21$ & 5 & 6 & 11 & 1388 & S7 & 19 & 26 & -1.1 & -0.3 \\
\hline $\mathrm{S} 22$ & 5 & -4 & 2 & 1000 & S7 & 19 & 59 & -9 & -21 \\
\hline $\mathrm{S} 23$ & 6 & 5 & 11 & 1665 & S8 & 16 & 30.3 & -0.8 & -1.1 \\
\hline $\mathrm{S} 24$ & 7 & 4 & 11 & 1665 & S9 & 13 & 32 & -2 & -1.6 \\
\hline $\mathrm{S} 25$ & 7.5 & 2.5 & 10 & 1665 & $\mathrm{~S} 10$ & 13 & 58 & -0.5 & -1.0 \\
\hline S26 & 8 & 4 & 11 & 1665 & $\mathrm{~S} 11$ & 13 & 30 & 0.7 & -1.6 \\
\hline S27 & 9 & 1 & 11 & 1665 & $\mathrm{~S} 12$ & 10 & 36 & -3.15 & -5.7 \\
\hline S28 & 11 & 1 & 11 & 1665 & $\mathrm{~S} 13$ & 10 & 57 & -2.0 & -5.7 \\
\hline
\end{tabular}

${ }^{\mathrm{a}}$ The trench location is measured with respect to the left-hand box side (Figure 3).

where $A_{0}^{d r y}$ is the preexponential factor for a zero water content, $\left[\mathrm{OH}^{-}\right]_{0}$ is a reference water content, set to the water amount dissolved by the mantle at the lithosphere-asthenosphere boundary $(\sim 100 \mathrm{~km}$ depth, $620 \mathrm{ppm}$ ), and $f_{\nu}$ is the maximum hydrous strength reduction. This simple parameterization was shown to trigger a rapid and strong convective thinning of the arc lithosphere, metasomatized by slab dehydration fluids, as soon as $f_{\nu} \geq 50$ (see section 3.1) [Arcay et al., 2006]. In this paper, this process is used to simulate a weakness area within the upper plate able to deform freely as a function of the arc stress regime. We thus set $f_{\nu}$ to 50 . Note that, if the effective non-Newtonian viscosity is expressed at constant dissipation rate $(\tau \dot{\varepsilon})$ instead of constant strain rate, the preexponential constant, $A_{0}$, in equation (4) becomes $A_{0}^{\frac{2}{2}}$. Consequently, for low water contents $(<0.15 \mathrm{wt} \%)$, the hydrous strength decrease is at most by the order of $9^{3 / 2} \sim$ 27 , whereas for high water contents $(>0.15 \mathrm{wt} \%)$, it is close to $f_{\nu}^{3 / 2} \sim 353$ [Arcay et al., 2006]. The range of strength reduction modeled for hydrated rocks is in agreement with laboratory experiments [e.g., Hirth and Kohlstedt, 1996]. We choose not to modify the crust strength as a function of water content in order to maintain the same yield stress increase along the subduction plane. The crust water content corresponds here to water absorbed by hydrated minerals, and is not associated with water pore pressure that should be included in Byerlee's law (3).

\subsection{Code and Numerical Resolution}

[16] Equations of conservation are solved with spline finite elements on a nondeforming rectangular grid (Eulerian code of Christensen [1992]). The $2220 \mathrm{~km}$ wide and $555 \mathrm{~km}$ deep simulation box is discretized into $508 \times 90$ nodes. The grid is refined to improve resolution in areas of high thermal and deformation gradients, i.e., in the vicinity of the subduction plane and in the mantle wedge tip area. 


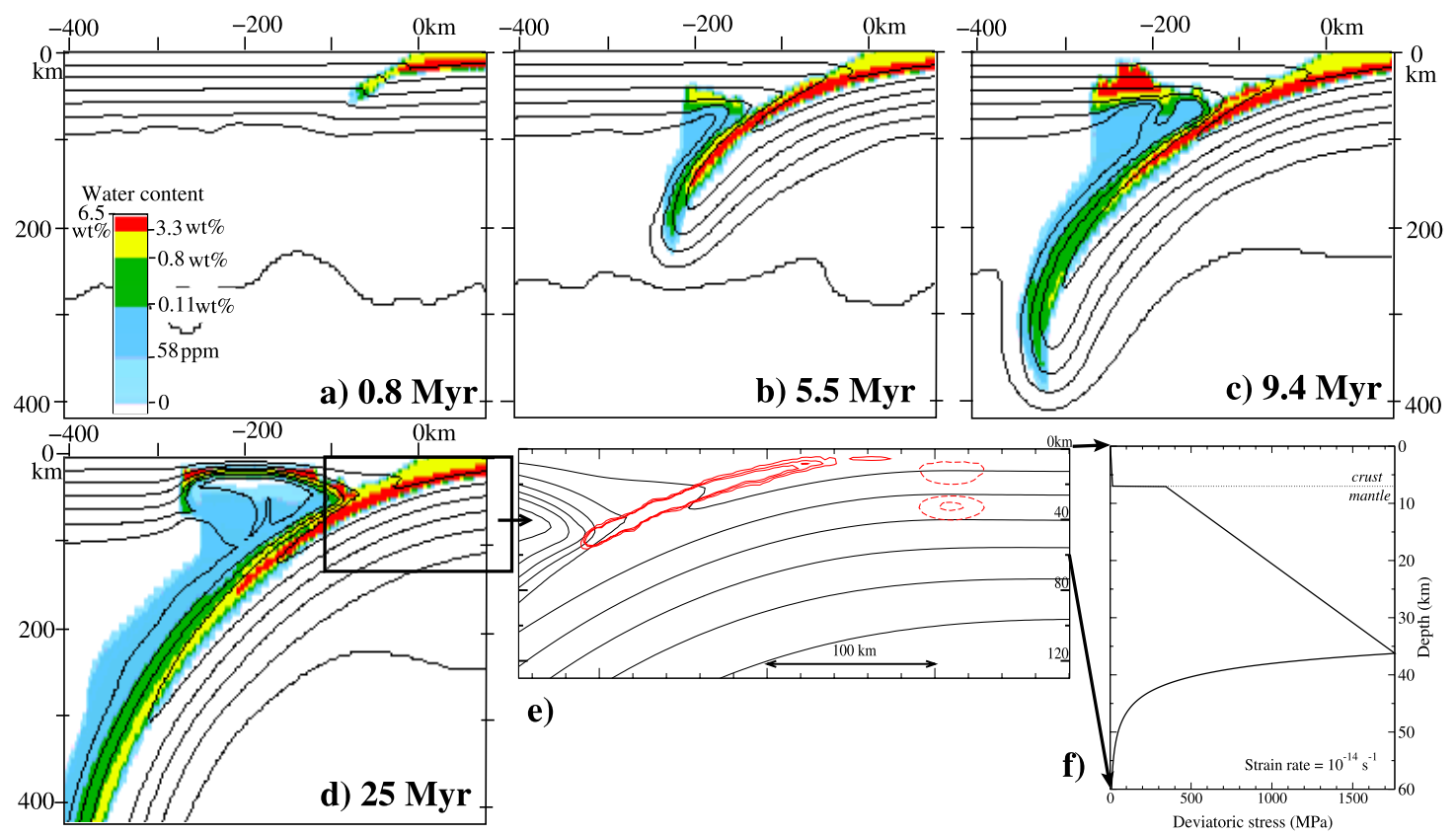

Figure 4. (a-d) Close-up on the subduction zone from initiation to steady state for simulation S1 (fixed upper plate, convergence rate of $5 \mathrm{~cm} / \mathrm{a}$, Table 2). Isotherms are depicted every $200^{\circ} \mathrm{C}$. The color scale highlights different processes of water absorption: red, water-rich mantle with stable minerals of serpentine and chlorite; yellow, nominally hydrated minerals stable in lesser proportions (phase $\mathrm{A}$ in the mantle, chlorite and amphibole in the gabbroic crust); green, stable hydrated minerals in low quantities (mantle amphiboles and phengite in the crust); blue and light blue, water absorbed by mantle dissolution in high quantities and very low amounts, respectively. (e) Zoom on the incoming plate structure in the vicinity of the trench $25 \mathrm{Ma}$ after subduction initiation. Red dotted lines represent outline of constant energy dissipation rate (one every $0.6 \mu \mathrm{W} \cdot \mathrm{m}^{-3}$ ). Along the subduction plane, dissipation rate outlines are depicted every $1.8 \mu \mathrm{W} \cdot \mathrm{m}^{-3}$ (solid dashed lines). (f) Profile of deviatoric stress across the incoming plate before plate bending at the trench, computed for the lithospheric temperature profile before bending and for a reference strain rate equal to $10^{-14} \mathrm{~s}^{-1}$.

As the trench is expected to move between $660 \mathrm{~km}$ and $1759 \mathrm{~km}$ away from the left-hand box side, the horizontal and vertical grid spacing are there equal to 2.85 and $2.26 \mathrm{~km}$, respectively, until $555 \mathrm{~km}$ depth. Outside this domain, they are equal to 9.5 and $10.2 \mathrm{~km}$, respectively. The tracer density is constant over the simulation box $\left(1\right.$ per $\left.\mathrm{km}^{2}\right)$. The minimum number of 7 tracers in the smallest mesh is sufficient to accurately determine the proportions of each tracer category in all meshes [Arcay et al., 2005].

\section{Simulation Reference and Terms of the Subduction Force Balance Modeled in This Study}

\subsection{Subduction Simulation From Initiation to Slab Steady State (Step 1)}

[17] We briefly describe how subduction develops from initiation to slab steady state, illustrated by simulation S1, performed with a fixed upper plate and a subduction rate of $5 \mathrm{~cm} / \mathrm{a}$ (Table 2). We focus on the arc lithosphere structure, that determines the arc strength.

[18] The progressive deepening and heating of the incoming plate triggers its dehydration. Serpentinite in the mantle slab is destabilized between 100 and $180 \mathrm{~km}$ depth, while crust eclogitization occurs between 60 and $80 \mathrm{~km}$ depth (Figures $4 \mathrm{~b}$ and $4 \mathrm{c}$ ). The overlying mantle wedge is rapidly water-saturated, because the mantle solubility in water does not exceed there $0.11 \mathrm{wt} \%$. The remaining dehydration water migrates toward the shallow part of the upper plate, where amphibole and serpentinite form at temperature lower than $1000^{\circ} \mathrm{C}$. The water content in the cold upper lithosphere is equal to at least $0.5 \mathrm{wt} \%$ (Figure 4c). As a consequence, the $1000^{\circ} \mathrm{C}$ isotherm within the hydrated lithosphere corresponds to a sharp water content increase upward, yielding a strong and 
localized viscosity decrease, due to the mantle strength dependency on water content. The $1000^{\circ} \mathrm{C}$ isotherm then acts as an intralithospheric decoupling level that destabilizes the hydrated lithosphere sublayer [Arcay et al., 2006] (Figure 4c). The continuous slab dehydration sustains through time the hydrated lithosphere ablation by underlying thermal convection cells. This process reduces the lithosphere thickness in the hydrated domain to $\sim 33 \mathrm{~km}, 25 \mathrm{Ma}$ after subduction initiation. Meanwhile, the subducting slab thermal structure reaches steady state at $\sim 19 \mathrm{Ma}$ (Figure $4 \mathrm{~d}$ ). Note that the process of upper lithosphere thinning is driven by thermal convection only, and is independent of the arc stress regime. The hot and hydrated area of the upper plate forms a weak zone, expected to laterally deform if local stresses exceed the thinned lithosphere strength. The hydrated lithosphere, located between 100 and $180 \mathrm{~km}$ away from the trench for a $5 \mathrm{~cm} / \mathrm{a}$ subduction rate, is assumed to simulate roughly the volcanic arc position. We thus label the thinned part of the upper plate the arc lithosphere.

\subsection{Energy Balance for the Subduction Zone and Forces Simulated in This Model}

[19] We derive a simple energy balance to assess the mechanisms of energy dissipation within the subduction zone. The purpose is to identify how kinematics modifies stress in the different areas of the subduction zone. The simulation box energy balance is derived from the conservation of momentum for a continuous medium (whose terms are multiplied by local velocity) integrated over the box volume [Conrad and Hager, 1999]. For a highly viscous fluid (low Reynolds number), the variation of kinetic energy with time is zero. The rate of mechanical energy release comes from (1) the variation of gravitational potential energy, $\Phi_{S P}$, and (2) the rate at which stresses do work along the box boundaries (depending on kinematic boundary conditions), $\Phi_{B C}$. This energy is consumed by subduction-induced mantle flow $\left(\Phi_{s m}\right)$ and by internal lithosphere deformation, $\Phi_{d}$. The balance between energy release and dissipation writes as: $\Phi_{S P}+\Phi_{B C}=\Phi_{s m}+\Phi_{d}$. The work done by the slab on the mantle $\left(\Phi_{s m}\right)$ includes both viscous and form drags $\left(\Phi_{\text {Stokes }}\right.$ and $\Phi_{\text {anchor }}$, respectively). We decompose the rate of energy dissipated by lithosphere internal deformation into shear heating along the interplate boundary, $\Phi_{\text {friction }}$, plate bending at the trench, $\Phi_{\text {bending, }}$, slab deep deformation, $\Phi_{\text {slab }}$, and arc strain, $\Phi_{a r c}$. The energy budget, by unit of trench perpendicular to the simulation box, writes as:

$$
\begin{aligned}
\Phi_{B C}= & \Phi_{\text {Stokes }}+\Phi_{\text {anchor }}+\Phi_{\text {friction }}+\Phi_{\text {bending }}+\Phi_{\text {slab }}+\Phi_{\text {arc }} \\
& -\Phi_{S P}
\end{aligned}
$$

To assess stress variations induced by surface kinematics from equation (6), we assume, when possible, that each rate of energy release/dissipation, $\Phi$, corresponds to the rate of work done at constant velocity by the associated force. For example, the energy release by the sinking of a cold thermal layer within the mantle is: $\Phi_{S P}=F_{S P}$ $\times v_{s}$, where $v_{S}$ is the subduction velocity and $F_{S P}$ is the slab-pull force. $F_{S P}$ depends on the subducting lithosphere age at the trench and on the subducted slab length [Turcotte and Schubert, 1982; Carlson et al., 1983; Conrad and Hager, 1999; Capitanio et al., 2007]: It is thus independent of convergence rate. This result implies that the modeled slab pull will be identical in all our simulations. In the following, each term in equation (6) is discussed to determine if, first, it can be approximated by the power of a force working at constant velocity, and second, when verified, if this force depends on surface kinematics. These forces are summarized in Figure 5. Note that the rate of plate convergence, $v_{c}$, is defined as a function of plate velocities far away from the subduction zone, i.e., whatever the trench velocity and the arc deformation: $v_{c}=v_{s u b}$ $v_{u p}$. The effective subduction rate at great depth, $v_{s}$, includes the rate of arc deformation, $v_{d}$, as arc spreading $\left(v_{d}>0\right)$ may accelerate subduction (and inversely for arc shortening). The subduction rate is thus $v_{s}=v_{c}+v_{d}$ (Figure 2).

\subsubsection{Viscous Heating by Subduction- Induced Mantle Flow}

[20] For an isoviscous mantle, the energy dissipated by the slab viscous drag, $\Phi_{\text {Stokes, }}$, scales with the square of the sinking velocity, $v_{s}$ [e.g., Conrad and Hager, 1999]. Although the modeled viscosity is non-Newtonian, we define $F_{\text {Stokes }}$ as the vertical component of the mantle resistance to subduction, increasing with the subduction rate, $v_{s}$. As the mantle strength rises with depth (equation (4)), the mantle Stokes reaction is expected to be maximum close to the box base. The dissipation by form drag, $\Phi_{\text {anchor }}$, results from the mantle reaction to slab lateral migration. By analogy to the mantle vertical resistive force, the energy dissipated by form drag is assumed to derive from the horizontal component of the mantle resistance, $F_{\text {anchor }}$ This force mimics the 


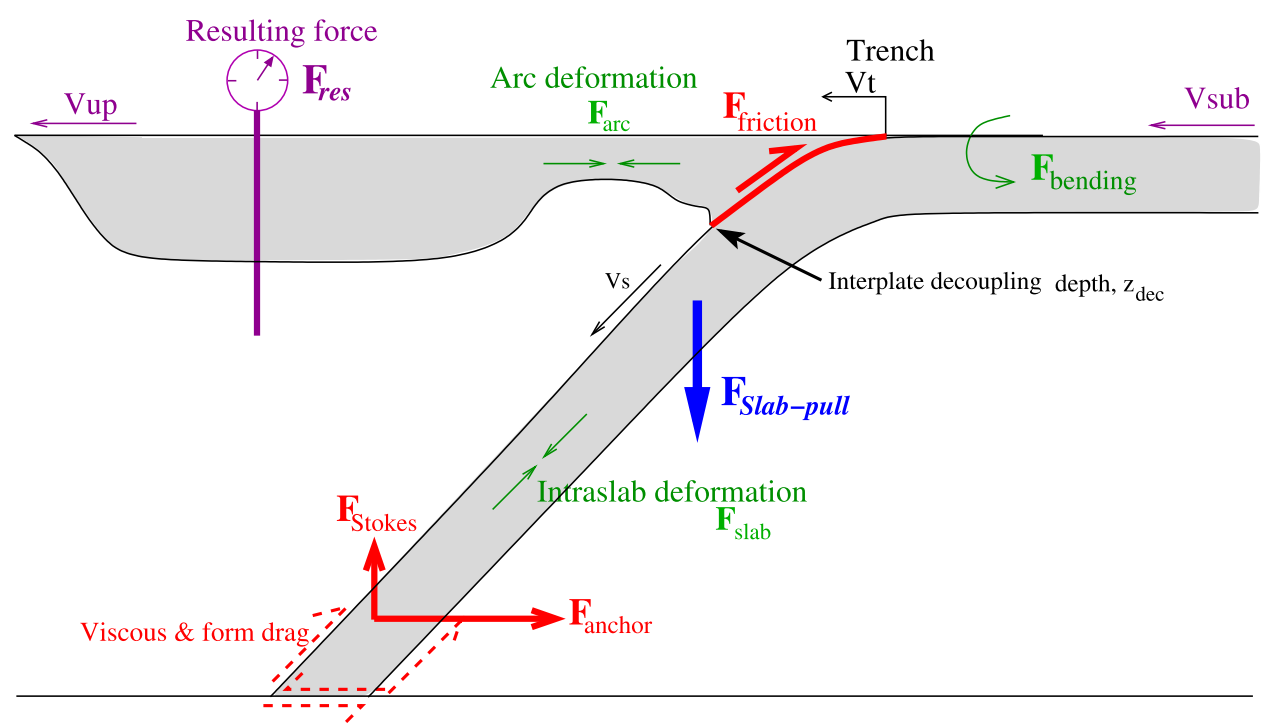

Figure 5. Sketch of driving (in blue) and resisting (in red) forces in a subduction system. Forces represented in green correspond to plate strength competing against deformation.

"slab anchor" described by Uyeda and Kanamori [1979]. If the arc lithosphere is neither stretched nor shortened $\left(v_{t} \sim v_{u p}\right)$, the form drag should increase with the upper plate velocity, $v_{u p}[$ Scholz and Campos, 1995]. Note that the zero horizontal velocity condition imposed along the open bottom boundary of the simulation box (Figure 3a, row 1) also competes against slab migration. We neglect here plate basal drag, i.e., the shearing occurring at the lithosphere-asthenosphere boundary, where the mantle viscosity is weak $\left(5 \times 10^{19}\right.$ Pa.s [Arcay et al., 2005]).

\subsubsection{Shear Heating Along the Interplate Surface}

[21] The frictional stress, given by equation (3), is independent of the slip along the interface contact. The shear heating rate at the interplate boundary is then: $\Phi_{\text {friction }}=F_{\text {Friction }} \times v_{s}$, where $F_{\text {friction }}$ is the total friction force at the interplate contact. $F_{\text {friction }}$ depends on the interplate segment length and on the interface rheology. The strength of the interplate boundary depends on the crust brittle yield stress increase with depth, $\gamma_{c}$ (equation (3)), constant in most simulations except in a few tests (Appendix A). The maximum extent of the interplate plane is controlled by the brittle-ductile transition depth along the subduction geotherm, and depends on the thermomechanical equilibrium at the mantle wedge tip [Conder, 2005; Arcay et al., 2007b]. We label the downdip limit of the interplate contact "the interplate decoupling depth," knowing that, at greater depth, the two converging plates are mechanically decoupled $\left(z_{d e c}\right.$ in Figure 5 [Furukawa, 1993]). In our modeling, the interplate decoupling depth was shown to decrease for increasing subduction rates [Arcay et al., 2007a, 2007b]. On one hand, low subduction rates slow the asthenospheric corner flow, thence the mantle heat flux advected toward the subduction plane. On the other hand, a low subduction velocity decreases frictional heating along the brittle interplate interface, by reducing strain rates, and further cools the subduction plane. Both effects result in the deepening of the interplate contact, and hence in the increase of the total frictional force. Therefore, although frictional stress does not depend on strain rate, the friction force is expected in our models to be a decreasing function of $v_{s}$. This assumes that variations of the subduction plane dip with convergence rate are weak.

\subsubsection{Dissipation by Lithosphere Bending}

[22] Figure $4 \mathrm{e}$ shows that plate bending mostly dissipates energy at depths shallower than $40 \mathrm{~km}$ at the outer bulge, i.e., in the plate brittle part much stiffer than the underlying viscous layer (Figure 4f). Before crossing the trench, the brittle-ductile transition depth within the oceanic plate only depends on the lithosphere geotherm 
[McNutt and Menard, 1982]. Consequently, the dissipation by bending may write as: $\Phi_{\text {bending }}=$ $F_{\text {bending }} \times v_{s}$, where $F_{\text {bending }}$ corresponds to the plate brittle strength, independent of convergence rate [Buffett, 2006]. By restricting our study to old plate subductions, the $F_{\text {bending }}$ force will be constant in all simulations as long as surface kinematics does not significantly modify the subduction plane dip.

\subsubsection{Dissipation by Deep Slab Deformation}

[23] The subducting slab may laterally deforms to accommodate trench motions (dip variations), as well as it might be stretched by the subducted material weight if the mantle support is not efficient. We cannot directly infer whether the slab strength, $F_{\text {slab }}$, at intermediate depth can be derived from the viscous dissipation rate, $\Phi_{\text {slab }}$, as strain decreases the slab strength. Nevertheless, this hypothetical force should increase with the subduction rate.

\subsubsection{Dissipation Within the Overriding Lithosphere}

[24] This last term of energy dissipation mainly originates from the thinned arc lithosphere deformation, as strain rates across the thick upper lithosphere are close to zero. We verified that dissipation in the pseudoridge area is negligible in the great majority of our simulations. The arc deformation velocity, $v_{d}$, is assumed to be either zero or roughly constant. We define the arc brittle-ductile resistance, $F_{\text {arc }}$, by: $\Phi_{\text {arc }}=F_{\text {arc }} \times$ $v_{d}$. $F_{\text {arc }}$ depends on the arc thermal and strain states (equation (4)). This last term varies through time as a function of mantle wedge dynamics.

[25] Finally, the work done by stress along the simulation box boundaries, $\Phi_{B C}$, in equation (6), compensates the difference between energy dissipation and release of the slab gravitational potential energy. If $\Phi_{B C}>0$, kinematic boundary conditions act to supply the missing energy necessary to sustain both the surface subducting plate speed and the upper plate velocity. On the contrary, $\Phi_{B C}<0$ when the subduction rate is lower than the "spontaneous" rate of slab sinking (uncompensated slab pull). We do not have access to the $\Phi_{B C}$ value through time. Instead, we compute the regional tectonic force, $F_{\text {res }}$, providing the energy rate $\Phi_{B C} . F_{r e s}$ is calculated from $\sigma_{x x}$ deviation from hydrostatic stresses in an oceanic column of density $\rho_{\text {ref }}$ [Christensen, 1992]:

$$
F_{\text {res }}=-\int_{0}^{z_{c}} \sigma_{x x} d z+\int_{0}^{z_{c}} \rho_{r e f}(z) z g d z
$$

where $z_{c}$ is the compensation depth $(259 \mathrm{~km})$ and $\sigma_{x x}$ is the horizontal normal component of stress tensor. $F_{\text {res }}$ is computed far away from the subduction zone (666 km away from the left box side), and used as a stress sensor in the upper plate. A low value of $F_{r e s}$ indicates that, if the subduction system was completely free to evolve, it could spontaneously produce a surface kinematics close to the applied one. Alternatively, very high values of $F_{\text {res }}\left(>10^{13} \mathrm{~N} / \mathrm{m}\right.$ in absolute value [Doin and Henry, 2001]) mean that the subduction kinematics cannot be self-sustained since it is critically driven by boundary conditions. The signed value of $F_{\text {res }}$ characterizes the upper plate tectonic regime from extension $\left(F_{r e s}>0\right)$ to compression $\left(F_{r e s}<0\right)$.

\subsubsection{Testing the Effect of Surface Plate Velocities: Short- Versus Long-Term Simulations}

[26] In the following sections, we investigate separately the influence of convergence rate, $v_{c}$ (section 4.1), and of upper plate velocity (section 4.3). We perform three different types of simulations. The first set of models simulates the subduction development at constant subducting plate velocity while the upper lithosphere is fixed (step 1 experiments). Simulations are stopped once the slab pull is stabilized (stable slab thermal structure). We then quantify stress in the upper lithosphere as a function of the subducting plate speed (section 4.1). The second and third sets of simulations aim at testing how the upper plate migration affects the arc stress. We vary the upper plate velocity $\left(v_{u p}\right)$, as well as the subducting plate velocity $\left(v_{\text {sub }}\right)$, keeping the convergence rate constant, from end of step 1 experiments. Both "instantaneous" simulations (second set of models, Table 3) and long-term experiments (third simulation set, Table 2) are performed with various combinations of $\left(v_{s u b}\right.$, $v_{u p}$ ). Instantaneous simulations are computed on short time durations ( $\leq 10^{5}$ years). They are helpful to test the subduction system reaction to a sharp kinematic change (section 4.3). Long-term simulations are still required to reveal how subduction evolves through time for different plate velocity combinations (section 5), because the subducting plate shape, the mantle wedge dynamics, and the 
Table 3. Subduction Short Simulations Performed to Test the Effect of Upper Plate Velocity

\begin{tabular}{|c|c|c|c|c|c|}
\hline Simulation & $\begin{array}{c}\text { Starts } \\
\text { From } \\
\text { Simulation }\end{array}$ & $\begin{array}{l}\text { Subduction } \\
\text { Age at } \\
\text { Onset, Ma }\end{array}$ & $\begin{array}{l}\text { Convergence } \\
\text { Rate } v_{c}, \mathrm{~cm} / \mathrm{a}\end{array}$ & $\begin{array}{c}\text { Upper Plate } \\
\text { Velocity } \\
v_{u p} \mathrm{~cm} / \mathrm{a} \\
\end{array}$ & $\begin{array}{c}\text { Subducting } \\
\text { Plate Velocity } \\
v_{\text {sub }}, \mathrm{cm} / \mathrm{a}\end{array}$ \\
\hline $\mathrm{S} 2 \mathrm{~b}$ & S2 & 76 & 1 & -1 & 0 \\
\hline $\mathrm{S} 2 \mathrm{c}$ & S2 & 76 & 1 & 2 & 3 \\
\hline S2d & S2 & 76 & 1 & 4 & 5 \\
\hline S2e & S2 & 76 & 1 & 5 & 6 \\
\hline S4b & S4 & 58 & 1.6 & -1 & 0.6 \\
\hline $\mathrm{S} 4 \mathrm{c}$ & S4 & 58 & 1.6 & 1 & 2.6 \\
\hline S4d & S4 & 58 & 1.6 & 2 & 3.6 \\
\hline S4e & S4 & 58 & 1.6 & 4 & 5.6 \\
\hline S4f & S4 & 58 & 1.6 & 5 & 6.6 \\
\hline S6b2 & S6 & 30 & 3 & -3 & 0 \\
\hline S6c & S6 & 30 & 3 & -2 & 1 \\
\hline S6d & S6 & 30 & 3 & -1 & 2 \\
\hline S6e & S6 & 30 & 3 & 2 & 5 \\
\hline S6f & S6 & 30 & 3 & 4 & 7 \\
\hline S7b & S7 & 19 & 5 & -5 & 0 \\
\hline S7c & S7 & 19 & 5 & -2 & 3 \\
\hline S7d & S7 & 19 & 5 & -1 & 4 \\
\hline S7e & S7 & 19 & 5 & 2 & 7 \\
\hline S7f & S7 & 19 & 5 & 4 & 9 \\
\hline S7g & S7 & 19 & 5 & 5 & 10 \\
\hline $\mathrm{S} 9 \mathrm{~b}$ & S9 & 13 & 7 & -7 & 0 \\
\hline S9c & S9 & 13 & 7 & -5 & 2 \\
\hline S9d & S9 & 13 & 7 & -2 & 5 \\
\hline S9e & S9 & 13 & 7 & -1 & 6 \\
\hline S9f & S9 & 13 & 7 & 2 & 9 \\
\hline S9g & S9 & 13 & 7 & 4 & 11 \\
\hline S9h & S9 & 13 & 7 & 5 & 12 \\
\hline $\mathrm{S} 12 \mathrm{~b}$ & S12 & 10 & 9 & -9 & 0 \\
\hline $\mathrm{S} 12 \mathrm{c}$ & S12 & 10 & 9 & -7 & 2 \\
\hline S12d & $\mathrm{S} 12$ & 10 & 9 & -5 & 4 \\
\hline S12e & S12 & 10 & 9 & -2 & 7 \\
\hline S12f & S12 & 10 & 9 & -1 & 8 \\
\hline S12g & S12 & 10 & 9 & 2 & 11 \\
\hline $\mathrm{S} 12 \mathrm{~h}$ & S12 & 10 & 9 & 4 & 13 \\
\hline $\mathrm{S} 12 \mathrm{i}$ & $\mathrm{S} 12$ & 10 & 9 & 5 & 14 \\
\hline
\end{tabular}

arc lithosphere structure depend on local thermomechanical equilibria, that slowly process due to temperature diffusion, and imply complex feedbacks between mechanical state and thermal structure.

\section{Model Sensitivity to Surface Plate Velocity}

\subsection{Influence of Convergence Rate at Subducting Slab Steady State for a Motionless Upper Plate (Step 1)}

[27] We describe the convergence rate influence on subduction force balance while the upper plate velocity is set to zero. The convergence rate, $v_{c}$, (equal to $v_{s u b}$ here) is increased from $1 \mathrm{~cm} / \mathrm{a}$ to
$11 \mathrm{~cm} / \mathrm{a}$ (simulations S1-S13, Table 2). The resulting force displayed in Figure $6 \mathrm{a}, F_{\text {res }}^{950 \mathrm{~km}}$, as a function of $v_{c}$, is obtained when the slab structure is steady state, i.e., when the subducting slab length is close to $950 \mathrm{~km}$.

[28] For very low convergence rates $\left(v_{c}<1.6 \mathrm{~cm} /\right.$ a), the tectonic force is extensive. For greater subduction rates, the subduction zone is compressive. However, the compressive resulting force does not increase monotically with $v_{c}$, and oscillates around $-5 \times 10^{12} \mathrm{~N} / \mathrm{m}$ for convergence rates exceeding $5 \mathrm{~cm} / \mathrm{a}$. In these cases, we systematically detect surface deformation either in the arc lithosphere and/or in the vicinity of the trench. Horizontal deformation velocities vary from -0.05 to $-0.3 \mathrm{~cm} / \mathrm{a}$ and indicate compressive strain. We assume that the threshold of $-5 \times 10^{12} \mathrm{~N} / \mathrm{m}$ 

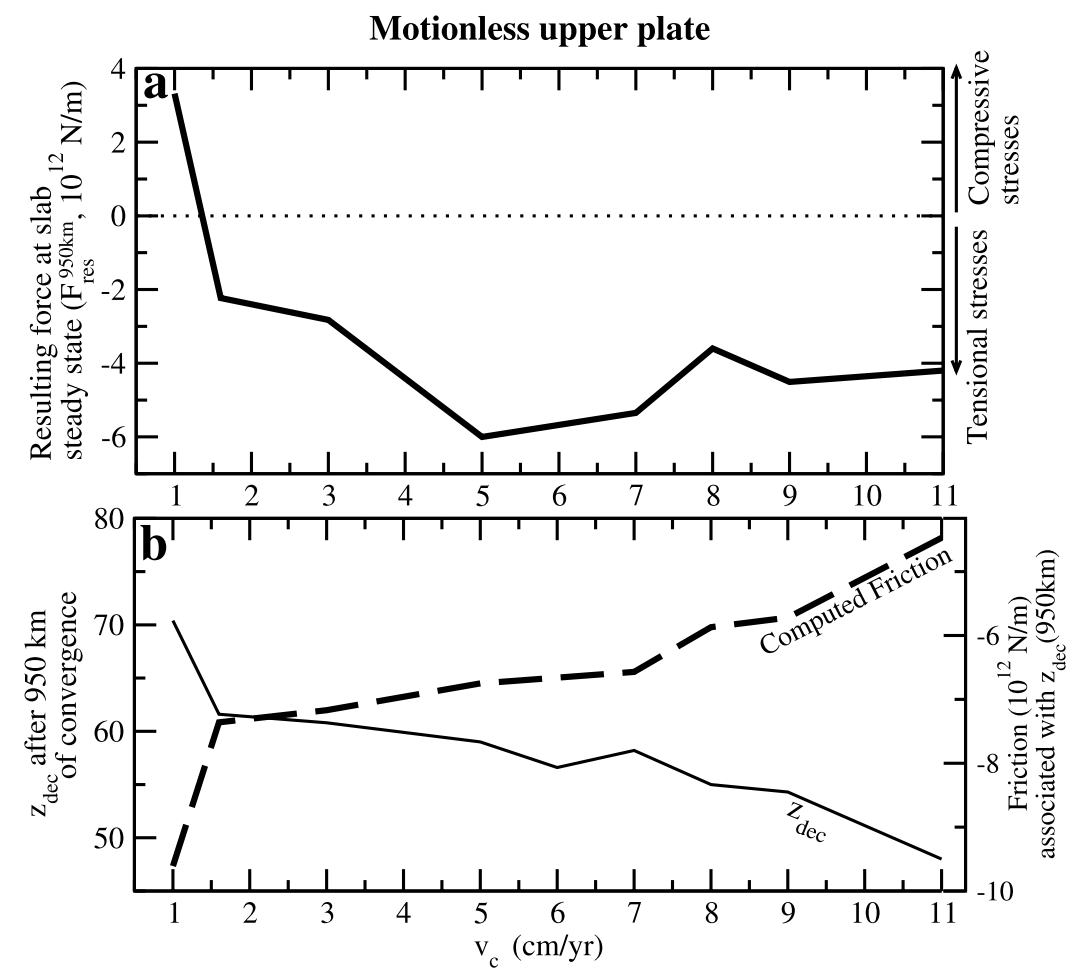

Figure 6. Influence of convergence velocity, $v_{c}$, on the subduction force balance for a motionless upper plate (simulations S1-S13, Table 2). (a) Resulting force obtained when the subducted slab length is close to $950 \mathrm{~km}$, $F_{r e s}^{950 \mathrm{~km}}$. (b) Interplate plane depth, $z_{d e c}$, and corresponding friction force estimate following equation (8) as a function of convergence rate, $v_{c}$, for a subducted slab length equal to $\sim 950 \mathrm{~km}$. Note that the values obtained for simulations S5 and S7 are not included. In these two simulations, the initial trench location is much closer to the left closed box side and induces an excess of compression by boundary effects.

corresponds to the average yield strength of the mantle arc lithosphere area at $\sim 950 \mathrm{~km}$ of convergence. Simulation S1, carried on $21 \mathrm{Ma}$ after the subducted slab length has reached $950 \mathrm{~km}$, shows that the resulting thickening of the arc lithosphere is canceled by the underlying thermal convective ablation constantly sustained by the mantle wedge hydration. As a consequence, the arc lithosphere strength remains more or less constant through time, which may explain the maximum compressive force simulated for all convergence rates greater than $5 \mathrm{~cm} / \mathrm{a}$.

[29] The convergence rate that minimizes the absolute value of $F_{\text {res }}$ is $\sim 1.4 \mathrm{~cm} / \mathrm{a}$ (Figure $6 \mathrm{a}$ ), and represents the boundary between extensive and compressive regimes for a motionless upper plate after $950 \mathrm{~km}$ of convergence. For comparison, the convergence velocity yielding the absence of significant arc stress for $v_{u p}=0$ is $\sim 5 \mathrm{~cm} / \mathrm{a}$ in current subduction zones (Figure 1). This suggests that the modeled subduction force balance is too compressive on average. In the section 4.2 , we present an estimate of the modeled friction force to highlight how this latter contributes in high compressive stress.

\subsection{Variations of the Modeled Friction Force}

[30] As mentioned in section 3.2, the friction force depends on the maximum depth of the interplate boundary, $z_{d e c}$, that controls the subduction plane length and where the yield stress is maximum. To calculate simply a rough estimate of the friction force, $F_{\text {friction }}$, we neglect here variations in the subduction dip angle, $\phi$, with the convergence rate. The subduction plane dip is set to its initial value $\left(30^{\circ}\right) . F_{\text {friction }}$ writes as a function of the crust yield stress along the interplate plane (equation (3)):

$$
\begin{aligned}
F_{\text {friction }} & =-\int_{0}^{z_{\text {dec }}} \frac{1}{\sin \phi}\left(\tau_{0}+\gamma_{c} \rho_{m} g z\right) d z \\
& =-\left(2 \tau_{0} z_{\text {dec }}+\gamma_{c} \rho_{m} g z_{\text {dec }}^{2}\right)
\end{aligned}
$$

The interplate decoupling depth, $z_{\text {dec }}$, after $950 \mathrm{~km}$ of convergence is estimated by measuring the 


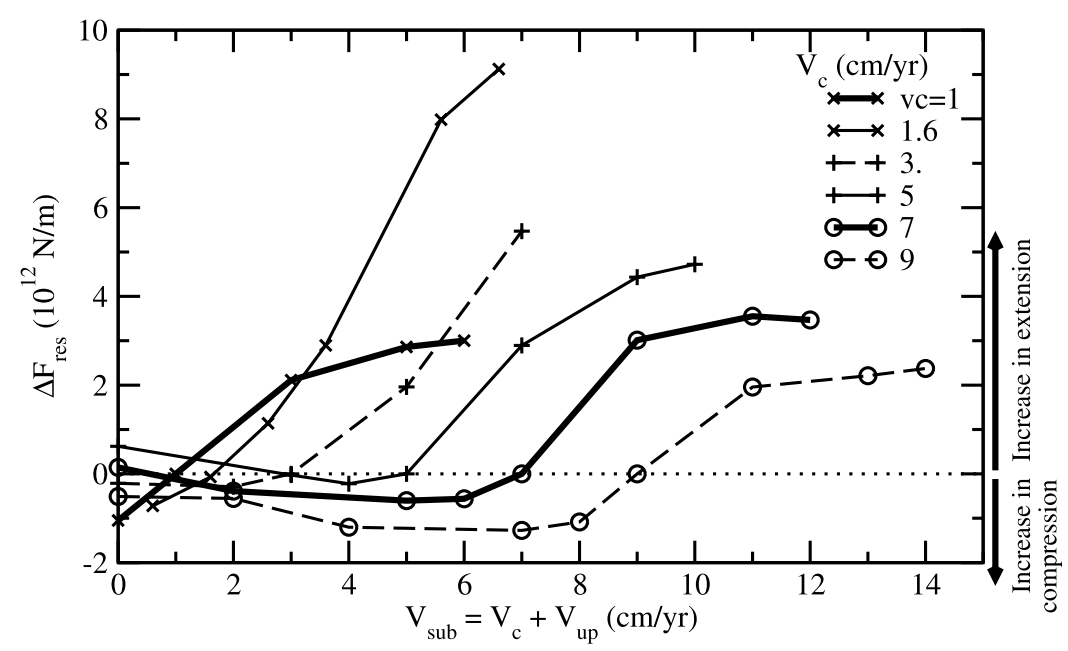

Figure 7. Influence of upper plate velocity on the resulting force while the convergence rate, $v_{c}$, is unchanged. The resulting force evolution is represented with respect to the value simulated for a motionless upper plate: $\Delta F_{\text {res }}=$ $F_{\text {res }}^{\text {vup }}-F_{\text {res }}^{\text {vup }=0}$.

depth where the shear heating rate is maximum along the interplate plane (Figure 6b) [Arcay et al., 2007b]. Compared to the $z_{d e c}$ decrease with $v_{c}$ shown by Arcay et al. [2007b] in the absence of water transfer computation, Figure $6 \mathrm{~b}$ shows that the interplate decoupling depth decrease with convergence rate is strongly enhanced by intense convective ablation of the hydrated arc lithosphere base: $z_{d e c}$ decreases from $70 \mathrm{~km}$ to $47 \mathrm{~km}$ as $v_{c}$ increases from 1 to $11 \mathrm{~cm} / \mathrm{a}$. For the range of investigated convergence rates, the computed friction force amplitude is greater than $4.5 \times$ $10^{12} \mathrm{~N} / \mathrm{m}$, and is closed to $10^{13} \mathrm{~N} / \mathrm{m}$ in the $1 \mathrm{~cm} / \mathrm{a}$ convergence rate case (Figure 6b). The friction force is thus a first-order term in the subduction force balance, even if the chosen crust friction coefficient is low (see section 2.3.1). In Appendix A, we accurately compare our friction force estimate, $F_{\text {friction }}^{\text {computed }}$, to the effective contribution of friction in the modeled subduction force balance, by studying the subduction zone behavior when friction is canceled. The analysis developed in Appendix A suggests that, for very low convergence rates $(<2 \mathrm{~cm} / \mathrm{a})$, the main force competing against slab pull is the friction strength along the subduction plane. To a lesser extent, the slab stretching occurring for hot and slowly subducting slabs $\left(v_{c}<1.6 \mathrm{~cm} / \mathrm{a}\right)$ also partly accommodates the slab pull. For high convergence rates $(>5 \mathrm{~cm} / \mathrm{a})$, the deep mantle strength efficiently compensates the subducted material weight. However, the interplate friction, despite the $z_{d e c}$ decrease, still contributes to rise compressive stress in the arc lithosphere. When the convergence rate is increased, the mantle ductile resistance rising and the friction force decrease could yield a maximum in compression for a subduction rate encompassed between 6 and $10 \mathrm{~cm} / \mathrm{a}$, possibly around $8 \mathrm{~cm} / \mathrm{a}$ (Figure 6a).

\subsection{Resulting Force as a Function of $\left(v_{s u b}, v_{u p}\right)$ for a Given Constant Convergence Rate: Instantaneous Simulations}

[31] We compare simulations performed with identical convergence rates and different upper plate velocities, $v_{u p}$. Simulations S2, S4, S6, S7, S9, and S11 performed for a motionless upper plate are carried on with a new combination of plate velocities at surface $\left(v_{s u b}, v_{u p}\right)$ for a short period of time (lower than $10^{5} \mathrm{a}$ ), to estimate the instantaneous subduction stress field (Table 3). Simulations with a zero upper plate velocity (step 1) are used as a reference to quantify the upper plate velocity effect on the resulting force jump, $\Delta F_{\text {res }}$ (Figure 7). Upper plate retreats are modeled in cases where $v_{s u b}>v_{c}$ to keep $v_{c}$ the same. Upper plate advance trenchward $\left(v_{u p}<0\right)$ corresponds to experiments performed with $v_{s u b}<v_{c}$ for the same reason.

[32] For all convergence rates, $\Delta F_{\text {res }}$ is positive for upper plate retreats and increases with $v_{u p}$. Modeling an upper plate retreat is equivalent to exert an extensive force on the subduction system [Chase, 1978], whose value increases with $v_{u p}$. In the same way, the upper plate trenchward advance increases compressive stress in the upper plate in most cases, as already suggested by Scholz and Campos 
[1995]. However, the compression increase appears to be buffered, and even canceled for fast upper plate trenchward advances. This result cannot be completely interpreted here. We think that the buffering in compression could derive from the subduction zone strength simulated in instantaneous calculations. The strain field modeled for upper plate trenchward advance on very short simulations might not correspond to a real equilibrium state, especially if kinematic boundary conditions impose a high compressive stress. Therefore, the nonNewtonian behavior is likely to be inaccurately modeled. Nevertheless, the resulting force sensitivity to upper plate velocity suggests that the modeled deep slab anchoring is high. When combined together, the basal slab anchoring and upper plate motion are able to turn a compressive state into an extensive stress regime (and vice versa) if the upper plate migration rate is high enough.

\section{Long-Term Subduction Evolution for Various Combinations of Plate Velocities}

[33] We study how thermal and mechanical structures over the subduction zone equilibrate through time in response to surface plate kinematics (Table 2). We focus on three combinations of plate velocities that produce three different tectonic regimes in the arc lithosphere: "neutral," highly compressive, and highly extensive. These three models simulate the plate kinematics estimated in the HS3 reference frame for the Kuril, Colombia, and Sandwich subduction zones [Heuret and Lallemand, 2005]. The thermal and mechanical evolution of the arc lithosphere is discussed in relation to the tectonic regional force $\left(F_{\text {res }}\right)$, the arc lithosphere thickness $\left(\Delta z_{\mathrm{min}}^{a r c}\right)$ considered as an indicator of the arc strength, the trench velocity $\left(v_{t}\right)$, the horizontal deformation rate simulated in the arc area $\left(v_{d}\right)$, and the subduction rate $\left(v_{s}\right.$, Figure 2). In the last subsection, we summarize the subduction model behavior as a function of surface velocities.

\subsection{Neutral Case Study}

[34] The subducting plate velocity, $v_{\text {sub }}$, is fixed to $10 \mathrm{~cm} / \mathrm{a}$, while the upper plate retreats with respect to the trench at a constant rate, $v_{u p}$, of $2.5 \mathrm{~cm} / \mathrm{a}$ (Kuril subduction kinematics, simulation S25, Table 2). The simulation starts from the subduction state obtained in simulation S10 after 13 Ma of convergence performed with a rate of $7.5 \mathrm{~cm} / \mathrm{a}$ (Figure 8).
[35] Figure 9a displays the evolution of the trench position, $x_{t}$, in relation to trench location at simulation start. The trench velocity, $v_{t}$, is computed by derivating $x_{t}$ with respect to time (Figure 9b). The deformation velocity in the arc lithosphere, $v_{d}$, is the difference between upper plate velocity, $v_{u p}$, and trench velocity: $v_{d}=v_{u p}-v_{t}$ (Figure 2). The subduction rate within the mantle, $v_{s}$, writes as $v_{s}=$ $v_{s u b}-v_{t}$. As the upper plate retreats away from the subduction zone, the shallow subduction dip, initially equal to $27^{\circ}$, increases to $36^{\circ}$ (Figure 8 ). The trench constantly migrates at a rate close to $v_{u p}$ $(2.5 \mathrm{~cm} / \mathrm{a}$, Figure $9 \mathrm{~b}): v_{d}$ remains very low, even if the arc lithosphere strength decreases. The arc lithosphere thinning by thermal convection, sustained by continuous slab dehydration, reduces the arc lithosphere thickness to $\sim 15 \mathrm{~km}, 15 \mathrm{Ma}$ after simulation onset (Figure 9c). Note that we here estimate the arc thickness by the $1000^{\circ} \mathrm{C}$ isotherm depth. Choosing a hotter isotherm to define the arc thickness would have lead to strong oscillations though time because of continuous blob detachments [Arcay et al., 2006]. Since the arc lithosphere is very weak, the absence of deformation indicates that stress across the arc area is low, as indicated by the low tectonic regional force, whose absolute value is always lower than $3 \times 10^{12} \mathrm{~N} / \mathrm{m}$ (moderate compressive regime, Figure $9 \mathrm{c}$ ). The arc lithosphere thickening between 16 and $24 \mathrm{Ma}$ (Figure 9c) is not associated with shortening. The drastic arc lithosphere thinning reached at $16 \mathrm{Ma}$ results in an high conductive gradient across the rigid lid (heat flow of $145 \mathrm{~mW} \cdot \mathrm{m}^{-2}$ ). We assume that the underlying small-scale convection is not vigorous enough to cancel alone the conductive cooling from above. An episode of thermal thickening initiates in the arc, and finally stabilizes the arc lithosphere thickness at around $28 \mathrm{~km}$.

\subsection{Compressional Case Study}

[36] Simulation S22 models an upper plate trenchward migration at a rate of $-4 \mathrm{~cm} / \mathrm{a}$, while the subducting plate advances with a $2 \mathrm{~cm} / \mathrm{a}$ velocity, as observed in the Colombia subduction zone in the HS3 reference frame [Heuret and Lallemand, 2005]. The simulation starts from the subduction stage obtained after $19 \mathrm{Ma}$ of convergence in model S7 (Table 2). Since simulation start (Figure 10, $0.8 \mathrm{Ma}$ ), the upper plate advance yields a highly compressional regime, with a resulting force equal to $-9 \times 10^{12} \mathrm{~N} / \mathrm{m}$ (Figure 11c). The arc lithosphere shortens while the shallow subduction dip decreases (Figure 10, $11.7 \mathrm{Ma})$. The arc deformation rate reaches 


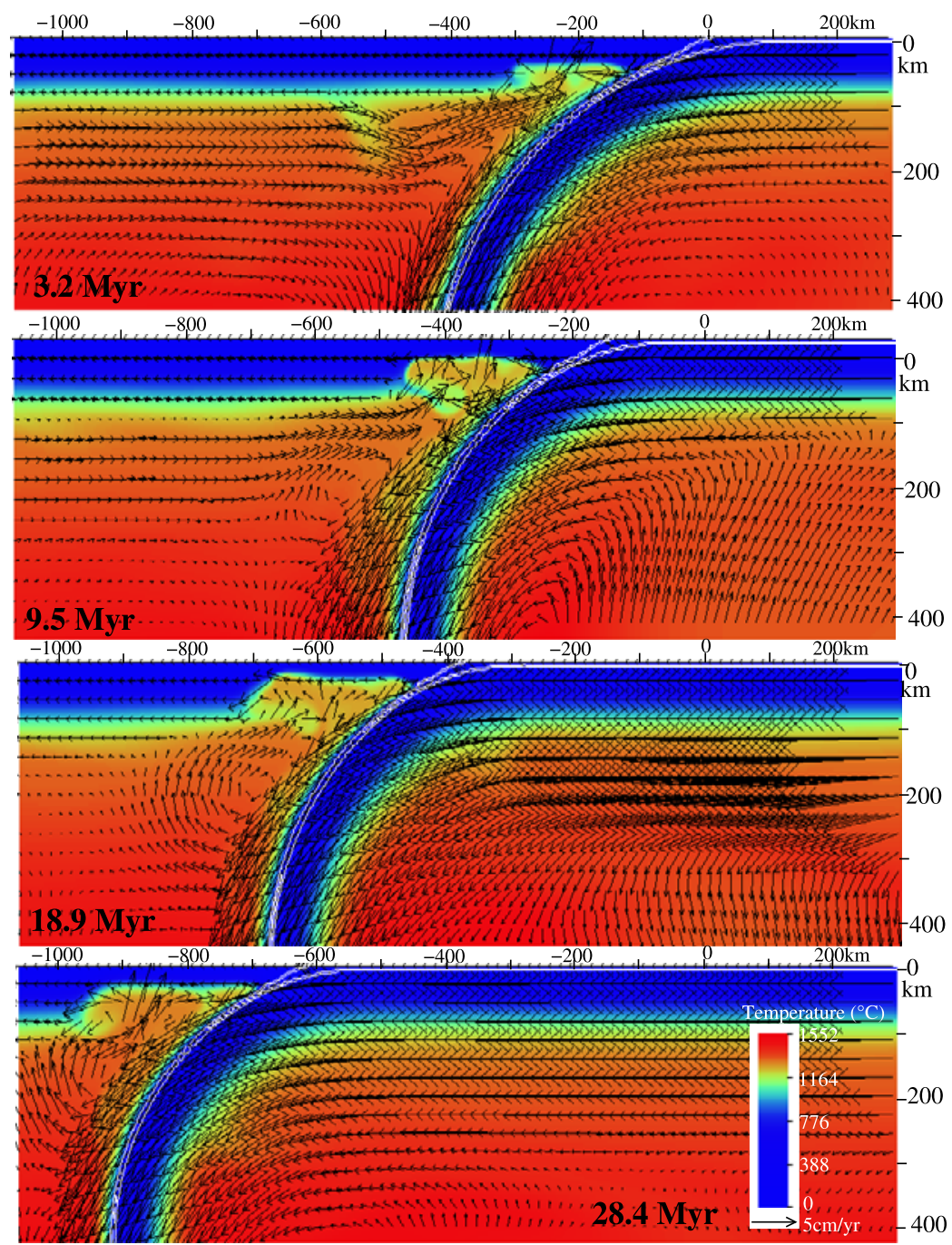

Figure 8. Evolution of the two converging plates in simulation S25 (Table 2) once the upper plate retreat at $2.5 \mathrm{~cm} /$ a is imposed: Zoom on the temperature and velocity field over the subduction zone at different times elapsed from simulation onset. The white line delimits the oceanic crust. The subducting plate velocity at surface is set $10 \mathrm{~cm} / \mathrm{a}$ to sustain a $7.5 \mathrm{~cm} / \mathrm{a}$ convergence rate.

$-0.5 \mathrm{~cm} / \mathrm{a}$ after $4 \mathrm{Ma}$ of convergence (Figure $11 \mathrm{~b}$ ), and results in the arc lithosphere thickening, from $25 \mathrm{~km}$ to $42 \mathrm{~km}$ (10.4 Ma, Figure 11c and Figure 10, $11.8 \mathrm{Ma})$. The arc shortening temporarily stops between $\sim 11$ and $15 \mathrm{Ma}$.

[37] The dip angle decrease is associated with the progressive mantle wedge closing, which impedes both thermal convection and asthenospheric corner flow. On one hand, the arc lithosphere cooling by shortening is unbalanced, and, on the other hand, the mantle wedge tip cools. This hinders the mechanical decoupling of the two converging plates at the subduction plane extremity. Therefore, the subduction dip decrease and the fore-arc lithosphere cooling triggers the subducting plate flat- tening. The force necessary to maintain high convergence velocities continuously rises to overcome the subduction zone cooling (Figure 11c). We observe the same irreversible evolution from subduction dip decrease to subducting slab flattening in simulation $\mathrm{S} 15$, performed with a $2.5 \mathrm{~cm} / \mathrm{a}$ upper plate trenchward advance (Table 2). In this modeling, the mantle wedge closing caused by upper plate advance, once initiated, cannot be canceled and leads to extremely high compressive stress $\left(-20 \times 10^{12} \mathrm{~N} / \mathrm{m}\right.$ after $20.5 \mathrm{Ma}$ of convergence, Figure 11c). If convergence was not forced by boundary conditions, the slab pull alone might not be able to overcome the strengthening of the cooled interplate plane and the subduction process might cease. 

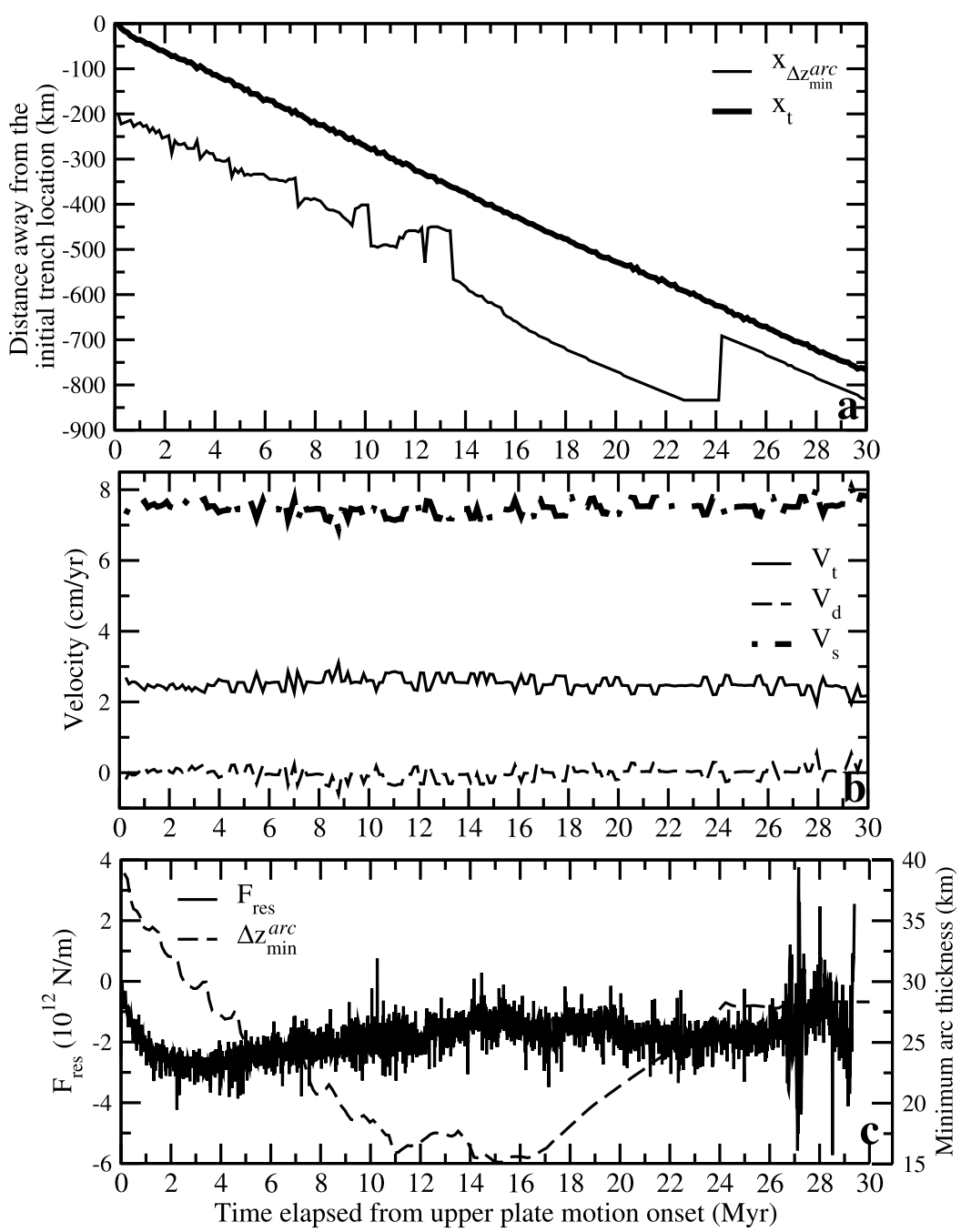

Figure 9. Evolution of trench position, surface velocities, and arc structure for simulation S25 (Table 2). (a) Trench location $\left(x_{t}\right)$ and position of the thinnest section within the arc lithosphere through time $\left(x_{\Delta z_{\min }}\right.$ ar $)$. Distances are measured with respect to the initial trench location at simulation start and are counted negatively toward the upper plate (as in Figure 8). (b) Evolution of trench velocity $\left(v_{t}\right)$, deformation velocity within the arc $\left(v_{d}\right)$, and velocity of slab subduction within the mantle $\left(v_{s}\right)$. (c) Resulting force of the subduction force balance, $F_{\text {res }}$, computed $666 \mathrm{~km}$ away from the left side of the simulation box, outside the area displayed in Figure 8, and minimum arc thickness, $\Delta z_{\min }^{a r c}$ (estimated by the depth of the $1000^{\circ} \mathrm{C}$ isotherm) at location $x_{\Delta z_{\min }^{\text {arc }}}$ (Figure 9a).

\subsection{Extensional Case Study}

[38] The kinematics of the Sandwich subduction zone is modeled by simulation S14 (Table 2). The upper plate velocity and the subducting plate velocity are set to $1 \mathrm{~cm} / \mathrm{a}$ and $2 \mathrm{~cm} / \mathrm{a}$, respectively. Simulation S14 starts from the final state obtained in simulation $\mathrm{S} 2$, performed with a $1 \mathrm{~cm} / \mathrm{a}$ rate convergence rate during $76 \mathrm{Ma}$ (Figure 12, $0.5 \mathrm{Ma}$ ). Simulation S14 exhibits three different stages, detailed in the following: (1) slow arc stretching (first $3 \mathrm{Ma}$ of convergence), (2) arc spreading at a constant velocity of $\sim 1.4 \mathrm{~cm} / \mathrm{a}$ (from $4 \mathrm{Ma}$ to $\sim 8 \mathrm{Ma}$, Figure 13b), and (3) arc spreading acceleration (last $4 \mathrm{Ma}$ of subduction). (1) At simulation start, the subduction system is highly extensive $\left(+4.8 \times 10^{12} \mathrm{~N} / \mathrm{m}\right.$, Figure $\left.13 \mathrm{c}\right)$. The resulting force immediately decreases, as the trench spontaneously rolls back. The trench velocity, $v_{t}$, decreases from the upper plate velocity $(1 \mathrm{~cm} / \mathrm{a})$ to $-0.3 \mathrm{~cm} / \mathrm{a}$ at $4 \mathrm{Ma}$ (Figure 13b). The arc lithosphere strongly thins (only $13 \mathrm{~km}$ after $3 \mathrm{Ma}$, Figure 13c), due to stretching by upper plate retreat and trench roll-back. As a result, the weak arc lithosphere fails, with a spreading center located $\sim 190$ away from the trench (Figure 12, 4.1 Ma). The arc spreading center will remain fixed until 

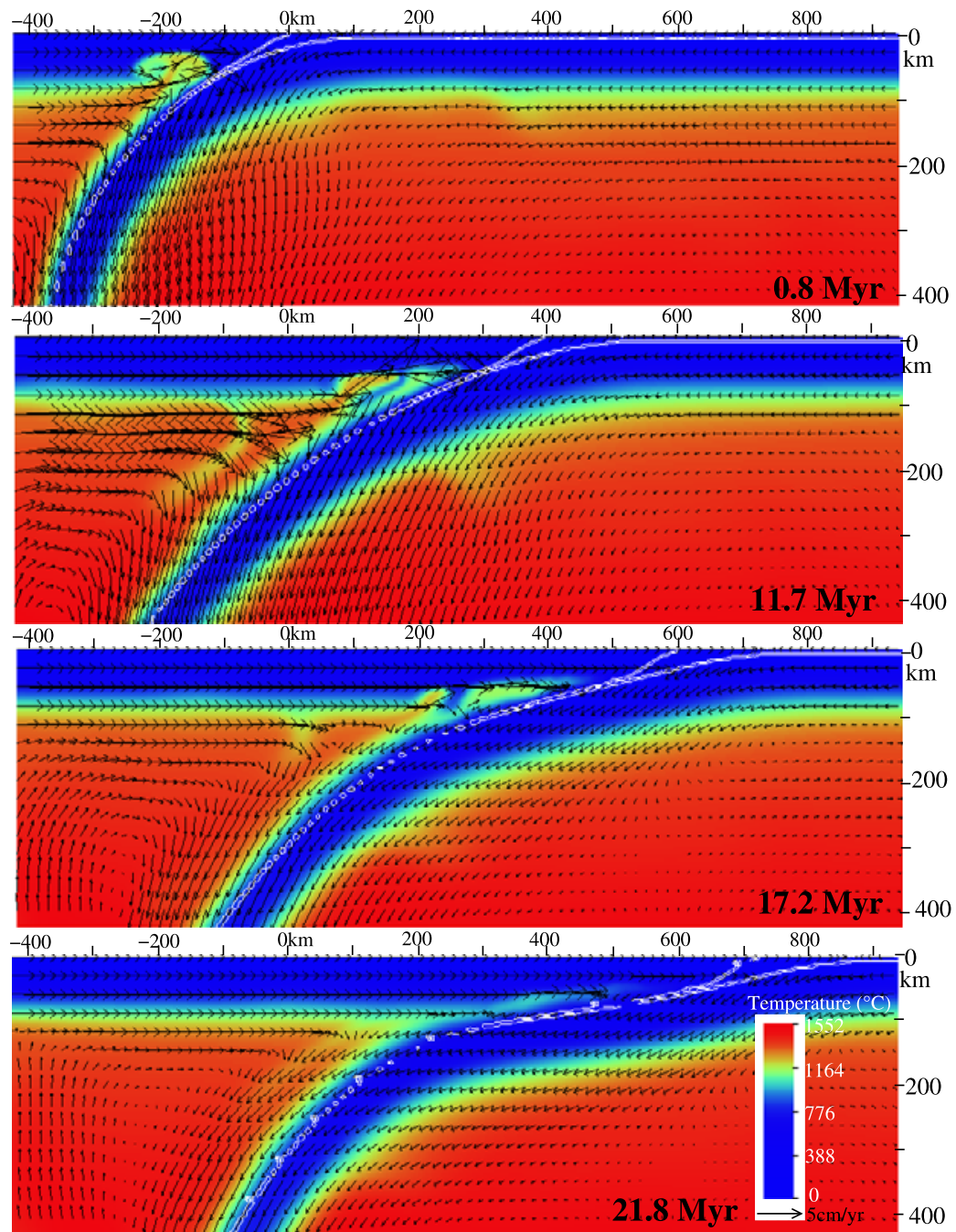

Figure 10. Same as Figure 8, for simulation S22 (Table 2): upper plate advance toward the trench at $4 \mathrm{~cm} / \mathrm{a}$, and subducting plate velocity at surface equal to $2 \mathrm{~cm} / \mathrm{a}$.

$\sim 8 \mathrm{Ma}$ after simulation start (Figure 13a). During phase 2, the sustained trench roll-back shallows the subduction dip at $60-150 \mathrm{~km}$ depth from $50^{\circ}$ at $4 \mathrm{Ma}$ to $\sim 37^{\circ}$, at $9 \mathrm{Ma}$ (Figure 12). Trench rollback increases the subduction rate $v_{s}(3 \mathrm{~cm} / \mathrm{a}$ at $7 \mathrm{Ma}$ ), which decreases the interplate decoupling depth from $70 \mathrm{~km}$ to $40 \mathrm{~km}$ (Figure 12, 4.1 Ma and $9 \mathrm{Ma}$ ) and the corresponding friction force (section 4.2). The resulting force thus rises from a low degree of compression $\left(-0.4 \times 10^{12} \mathrm{~N} / \mathrm{m}\right.$, $4 \mathrm{Ma})$ to become extensive at $10 \mathrm{Ma}(+0.4 \times$ $10^{12} \mathrm{~N} / \mathrm{m}$, Figure 13c). Note that extension, promoted by friction force decrease, is here partly counterbalanced by the mantle resistance increasing with $v_{s}$. This would explain why the resulting force increase is so low. (3) At $8 \mathrm{Ma}$, the arc lithosphere thickness is reduced to $3.6 \mathrm{~km}$ (Figure 13c): The arc lithosphere strength is canceled. Therefore, the trench roll-back velocity exponentially increases from $\sim 8 \mathrm{Ma}$ (Figure 13b). The associated subduction rate increase $(10 \mathrm{~cm} / \mathrm{a}$ at $10 \mathrm{Ma})$ favors cold material advection and, at a given depth, cools the newly subducted slab with respect to previous segments. The decrease of the deep subduction dip (Figure 12, 10.4 Ma) may result from the subducting slab cooling and strengthening.

\subsection{Synthesis: Influence of Surface Plate Kinematics on the Modeled Arc Strain Regime}

\subsubsection{Arc Compression Versus Extension Domains in Our Modeling}

[39] We summarize in Figure 14a the results obtained for long-term simulations listed in Table 2. Simulations are classified into four categories, depend- 

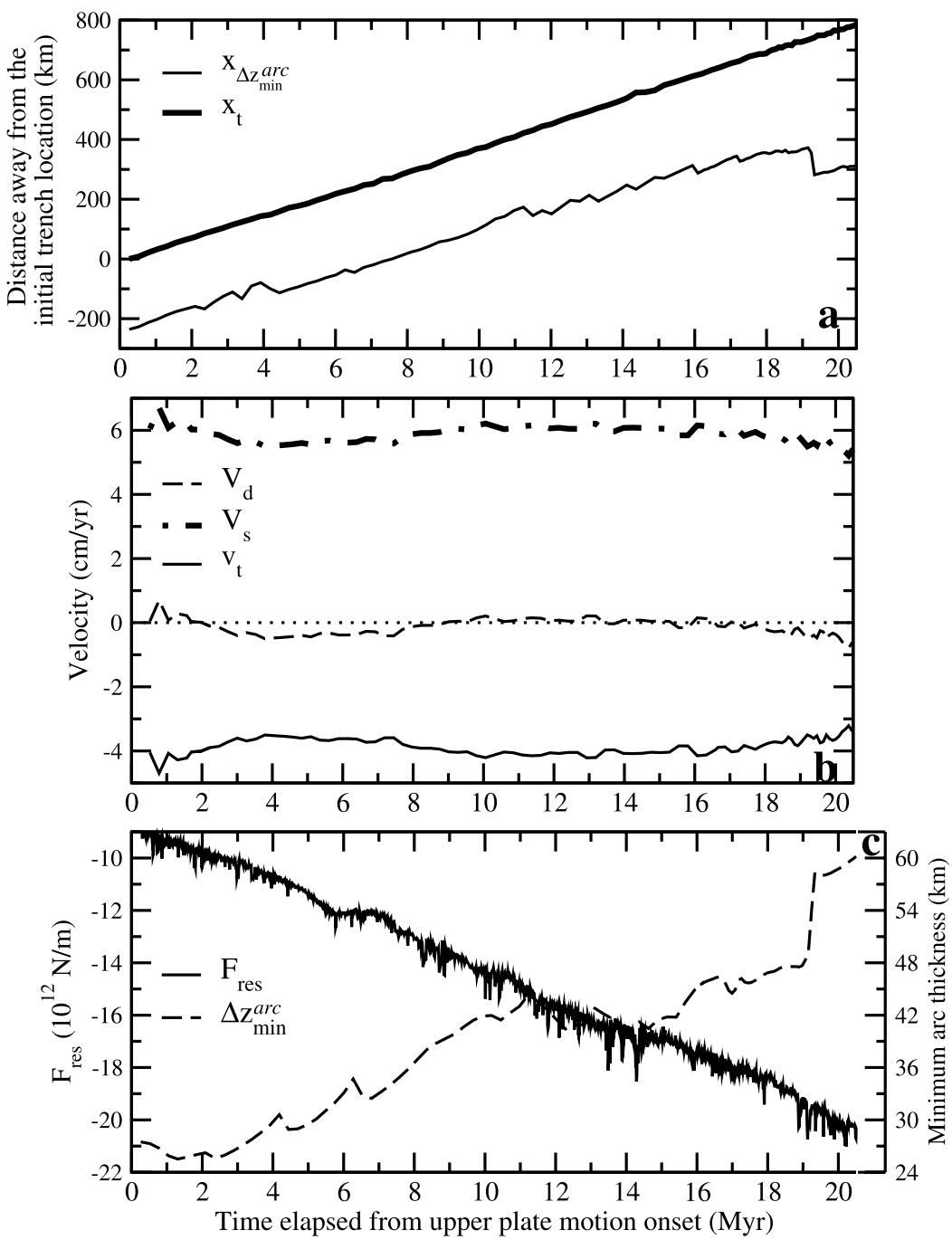

Figure 11. Same as Figure 9, for simulation S25 (Table 2).

ing on deformation velocity in the arc lithosphere $\left(v_{d}\right)$ and resulting force, $F_{r e s}$. "Extensive regime" is defined by a $F_{\text {res }}$ increase to a positive value associated with arc rifting or spreading $\left(v_{d}>0\right)$. "Weakly extensive" regime corresponds to a positive resulting force for which no deformation occurs $\left(v_{d}=0\right)$. "Low compression" corresponds to a zero arc strain and low negative resulting force $\left(-2 \times 10^{12} \leq F_{\text {res }}<-1 \times 10^{12} \mathrm{~N} / \mathrm{m}\right)$. "Compressive regime" includes simulations for which $F_{\text {res }} \leq$ $-2 \times 10^{12} \mathrm{~N} / \mathrm{m}$ and $v_{d}<0$. At last, the models for which $v_{d}$ is always close to zero (oscillations with amplitude $<0.8 \mathrm{~cm} / \mathrm{a}$ in absolute value), while the resulting force tends to zero, belong to the "neutral" domain. To compare modeling results to statistical trends observed in current subduction zones (Figure 1), simulations are depicted as a function of subducting and upper plate velocities applied at the box surface. Extensive regimes are obtained only for fixed or retreating upper plates (Figure 14a). As the subducting plate velocity increases, thus rising mantle resistance to subduction, the rate of upper plate retreat must increase to trigger spreading in the arc lithosphere. Compressive regime is modeled at any subducting plate velocity if the rate of upper plate retreat is low enough. Upper plate trenchward advance systematically leads to compression (section 5.2). We obtain only three models classified in the "neutral" regime, located at the boundary between compressive and extensive domains (Figure 14a). The regression line computed with these three points writes as: $v_{u p}=0.63 v_{s u b}-1$ (black line in Figure 14a), or, expressed as a function of convergence velocity (in $\mathrm{cm} / \mathrm{a}$ ):

$$
v_{u p}=1.7 v_{c}-2.7
$$




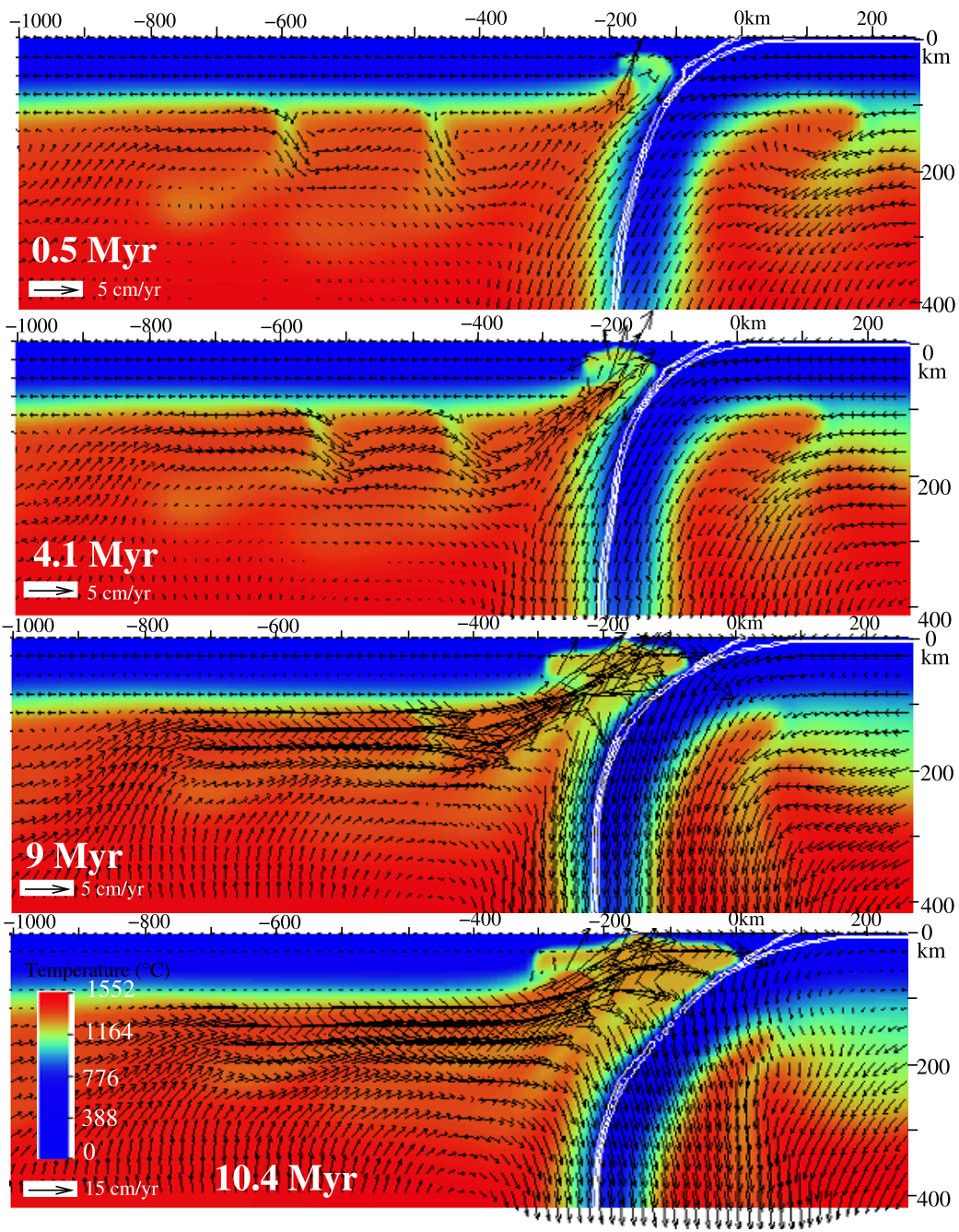

Figure 12. Same as Figure 8, for simulation S14 (Table 2): upper plate retreat with respect to the trench of $1 \mathrm{~cm} / \mathrm{a}$, and subducting plate velocity at surface equal to $2 \mathrm{~cm} / \mathrm{a}$ (model of Sandwich kinematics).

We have checked that the arc stress modeled as a function of plate velocities is not modified by a moderate change in the convergence rate $( \pm 1 \mathrm{~cm} / \mathrm{a})$ used to obtain the starting subduction state (step 1 experiment) at upper plate migration initiation (see Appendix B).

\subsubsection{Time Dependence of the Arc Strain Regime}

[40] To illustrate how the arc deformation mode may be time dependent, we describe simulation S6, performed with a fixed upper plate and a $3 \mathrm{~cm} / \mathrm{a}$ convergence rate (Figure 14b). When the slab pull is steady state, the resulting force equals $-2.7 \times$ $10^{12} \mathrm{~N} / \mathrm{m}$ and the arc deformation rate is zero (31.7 Ma after subduction onset). The simulation S6 stress regime is then labeled compressive in
Figure 14a. However, this arc stress regime is not stable on long durations. The resulting force becomes extensive at $37 \mathrm{Ma}$, and triggers stretching in the thinned arc lithosphere. We assume that the evolution from compression to extension results from the arc-fore-arc lithosphere dynamics. The degree of arc thermal thinning keeps on increasing after slab-pull stabilization, which implies two effects. First, the interplate decoupling depth decreases (from $61 \mathrm{~km}, 30 \mathrm{Ma}$, to $54 \mathrm{~km}$ at $40 \mathrm{Ma}$ ). The friction force is thus reduced (by $\sim 1.6 \times 10^{12} \mathrm{~N} / \mathrm{m}$, equation (8)). Second, the arc thermal weakening triggers arc shortening $\left(v_{d}=\right.$ $-1 \mathrm{~cm} / \mathrm{a}, 37.4 \mathrm{Ma})$. The latter leads to a subduction rate decreases, and thence to a weaker slab support by mantle strength. Both processes eventually trigger arc spreading. Hence, the simulation S6 evolution suggests that the arc stress regime 

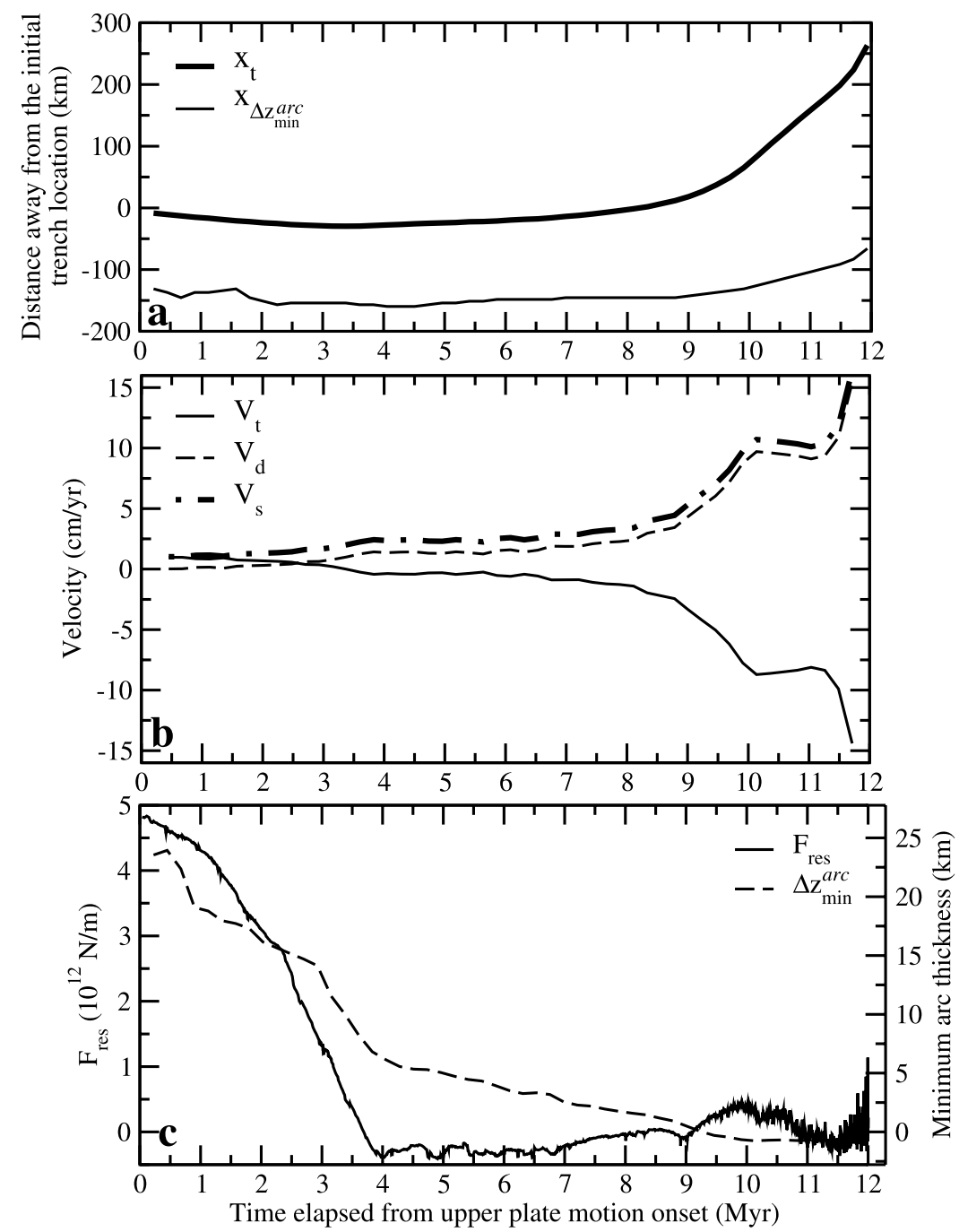

Figure 13. Same as Figure 9, for simulation S14 (Table 2).

modeled at $\sim 950 \mathrm{~km}$ of convergence is not necessarily stable. This instability comes from the dynamic feedback between arc deformation and amplitude of forces resistive to subduction (e.g., friction and mantle Stokes reaction).

[41] At slab steady state, a subduction rate $\geq 1.6 \mathrm{~cm} / \mathrm{a}$ is sufficient to simulate arc compression for a motionless upper plate. Simulation S6 with $v_{c}=$ 3 suggests that, on long subduction durations $(>20 \mathrm{Ma})$, the transition from extension to compression is shifted to a convergence velocity greater than $3 \mathrm{~cm} / \mathrm{a}$. We notice that model S6b (Table 2), performed with $v_{c}=4 \mathrm{~cm} / \mathrm{a}$, evolves from a compressive state at $950 \mathrm{~km}$ of convergence to an unstable subneutral regime on longer timescales (Figure 14b), whereas simulation S1 displays a compressive behavior at all times $\left(F_{\text {res }}<-2 \times\right.$
$10^{12} \mathrm{~N} / \mathrm{m}$ and $v_{d}<0$, Figure $14 \mathrm{~b}$ ). To conclude, the transition from extension to compression on lasting convergences, for a fixed upper plate, may occur at a subduction rate of $\sim 4 \mathrm{~cm} / \mathrm{a}$.

\section{Discussion}

\subsection{Influence of the Arc Lithosphere Strength}

[42] The arc spreading onset used to classify our subduction models in the extensional domain (Figure 14a) occur rapidly once the slab pull is stable (durations $\leq 5 \mathrm{Ma}$ from upper plate motion initiation). The boundary between compressive and extensive domains, expressed as a function of plate velocities (Figure 14a), is thus based on the shortterm subduction behavior. As discussed above, the 
convergence rate yielding a "neutral" regime, for a motionless upper plate, increases from $1.4 \mathrm{~cm} / \mathrm{a}$ on short timescales from slab pull steady state to 3 or even $4 \mathrm{~cm} / \mathrm{a}$ on long-duration convergences (see Figure 14b, b1 and b2). This shift comes from the fore-arc/arc lithosphere behavior through time. It highlights the critical influence of the arc lithosphere strength on the simulated subduction force balance. The modeled arc strength depends on (1) distribution of slab dehydration fluids across the arc area and arc metasomatism degree, (2) the arc lithosphere composition before hydration, allowing or not the formation of hydrated minerals at high temperature $\left(>900^{\circ} \mathrm{C}\right)$ necessary to trigger
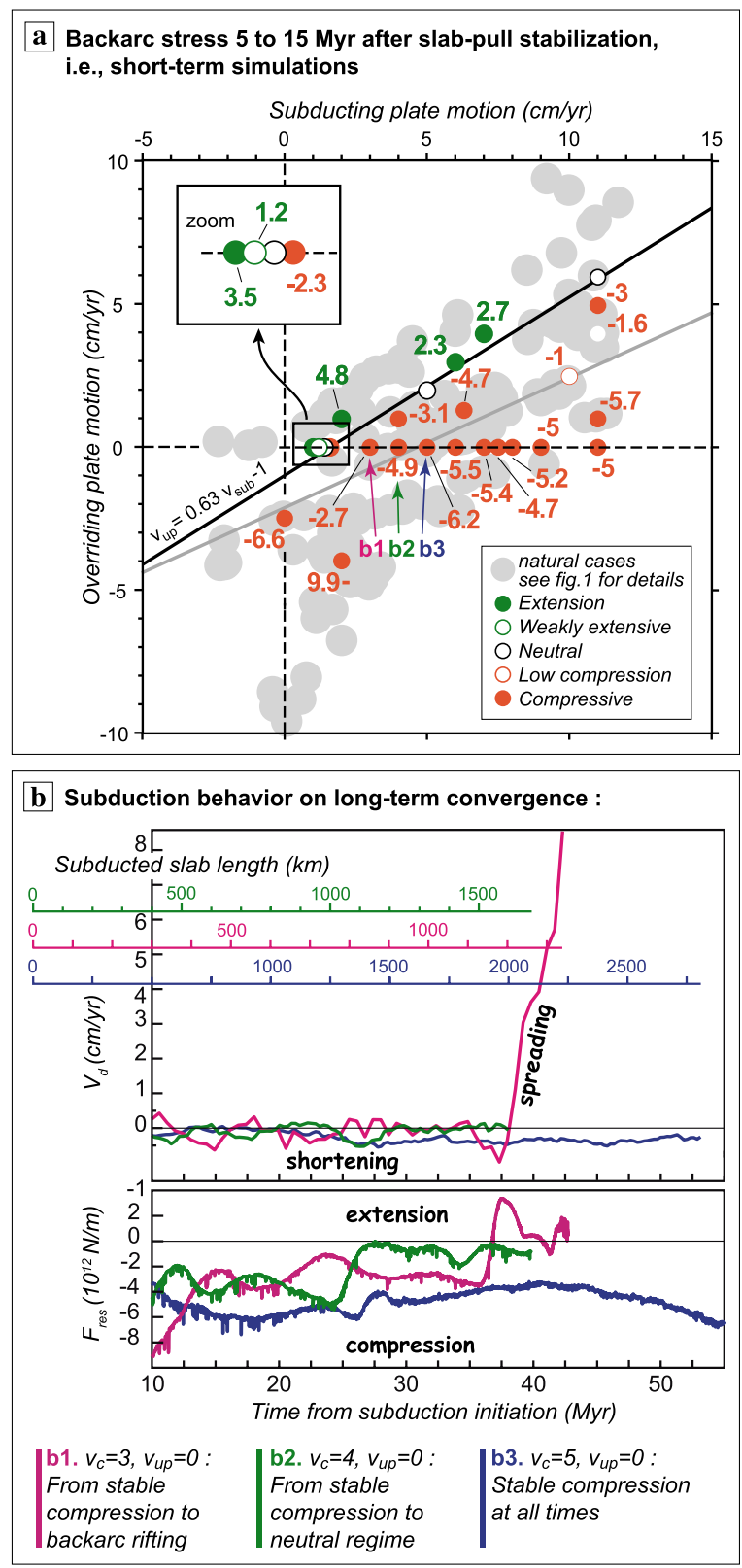

an intralithospheric decoupling level [Arcay et al., 2006], and (3) the strength reduction modeled for hydrated mantle rocks (equation (5)). Hence, the arc lithosphere strength is likely to strongly vary from a subduction zone to another, which we neglect in this paper. In this study, the geometry of the hydrated and weakened arc lithosphere is controlled by the convergence rate only (compare the first pictures of subduction with $v_{c}=7.5 \mathrm{~cm} / \mathrm{a}$, Figure 8 and with $v_{c}=1 \mathrm{~cm} / \mathrm{a}$, Figure 12). The subduction of a younger lithosphere would have reduced the hydrated domain width, but also maximized the slab dehydration degree, due to a more efficient slab top warming. Besides, note that the modeled arc lithosphere is only made of mantle. Including a shallow crustal structure should decrease the arc strength, possibly modifying the evolution of subduction force balance. We discuss in the following the compression-extension boundary modeled in this paper in relation to statistical trends observed in current subduction zones, being aware that the simulated arc strain rates cannot directly be compared to natural cases.

\subsection{Arc Strain Regime: Model Versus Statistical Trends on Modern Subductions}

[43] Compared to the relationship between $v_{s u b}$ and $v_{u p}$ describing the absence of arc deformation in current subduction zones, the modeled extensioncompression transition is, first, shifted toward higher rates of upper plate retreat with respect to the trench (compare the observed kinematic relationship equation (1), grey line in Figure 14a, and the modeled relation equation (9), black line in Figure 14a). Our subduction model may simulate

Figure 14. (a) Summary of long-term simulations of subduction listed in Table 2, depicted as a function of subducting plate velocity imposed at surface $\left(v_{\text {sub }}\right)$, upper plate velocity $\left(v_{u p}\right)$, and arc tectonic regime. Simulation results are superimposed on current subduction transect data (grey dots) displayed in Figure 1. Numbers refer to the resulting force $\left(F_{r e s}\right)$, in $10^{12} \mathrm{~N} / \mathrm{m}$, modeled at $950 \mathrm{~km}$ of convergence (slab pull steady state). See the text for class definition. The thick black line is the regression line among the simulations for which both arc horizontal deformation and resulting force are close to zero (defined as "neutral" tectonic regime), while the grey line is the regression line for current "neutral" subduction zones in HS3 reference frame (Figure 1). (b) Time evolution of resulting force and arc horizontal deformation at fixed overriding plate $\left(v_{u p}=0\right)$ for simulations $\mathrm{S} 6\left(v_{s u b}=v_{c}=3 \mathrm{~cm} / \mathrm{a}\right)$, simulation S6b $\left(v_{\text {sub }}=4 \mathrm{~cm} / \mathrm{a}\right)$, and $\mathrm{S} 1\left(v_{\text {sub }}=5 \mathrm{~cm} / \mathrm{a}\right)$. 
on average a compression degree higher than in natural magmatic arcs. Firstly, the mantle strength increase with depth, and/or the crust friction coefficient are possibly too high. However, a relatively high crust and mantle stiffness is required in our model to correctly compensate at great depths the cold lithosphere sinking, otherwise subduction cannot be simulated in a realistic way. The resulting force basically depends on the crust frictional coefficient and on the mantle viscous rheology (activation energy and activation volume; see Appendix C). Secondly, by modeling old and cold subducting lithospheres, the incoming plate can support high stresses before reaching the deformation threshold, due to a large plate strength. This might also explain why the influence of convergence rate, $v_{c}$, on subduction force balance is much higher than suggested by current observations (equation (9)): The subduction rate is the only parameter controlling in our model the subducting slab strength. At last, the simulated trenchward advance of upper plate enhances high compression in the arc lithosphere, in agreement with observations (Figure 1), but here triggers flat subduction. This excess in compression might originate from either a too strong deep slab anchoring, and/or a boundary effect caused by the closed left side of the simulation box facing the subducting slab, that could disturb the subduction-driven mantle flow. Despite the numerous limitations aforementioned, our simulations remain able to simulate a transition from arc compression to arc spreading for reasonable plate velocities at the surface, and, in some cases, to reproduce correctly the arc deformation mode observed in nature for a given kinematics (Kuril and Sandwich kinematics for example). We discuss bellow the different insights inferred from this model to subduction force equilibrium understanding.

\subsection{Subduction Force Balance Inferred From Statistical Trends: Insight From This Modeling}

[44] Our modeling differs from many subduction force models by the simulated rheology. At low temperature and shallow depth, the incoming plate strength is controlled by the brittle yield stress, that limits the energy dissipated by plate bending. As a result, the bending strength is not a predominant force balancing the slab pull in this model (contrary to Becker et al. [1999], Conrad and Hager [1999, 2001], Funiciello et al. [2003b], Bellahsen et al. [2005], Schellart [2005], Buffett [2006], and Faccenna et al. [2007]). We think that modeling the lithosphere yield stress at shallow depth is more realistic to simulate plate bending [Kohlstedt et al., 1995; Buffett and Rowley, 2006]. Consequently, the basic forces resistive to subduction are in our model the surrounding mantle strength and the friction force. The mantle Stokes reaction was argued to be the main force balancing slab pull by numerous authors [e.g., Scholz and Campos, 1995; Becker et al., 1999; Becker and O'Connell, 2001; Conrad and Lithgow-Bertolloni, 2002; Ribe, 2003; Bellahsen et al., 2005; Billen and Hirth, 2007]. Frictional stresses along the interplate surface are usually neglected in subduction force models. Note that the high proportion of friction appears despite our low crust frictional coefficient, which is besides in agreement with studies of conditions sustaining the subduction process [Bercovici, 1996; Tackley, 2000; Doin and Henry, 2001]. The friction force is here required to equilibrate slab pull especially for slow convergences for which the surrounding mantle ductile strength is weak. However, including in the model a lower mantle layer stronger than the upper mantle and/or a density jump [e.g., Richards and Hager, 1984; Christensen, 1996; Schmeling et al., 1999; Conrad and Lithgow-Bertolloni, 2002; Billen and Hirth, 2007] should enhance slab pull balance by mantle viscous shear and affect slab dip and trench velocity. A significant insight from our simulations is that subduction force balance is a time-dependent process if the intrinsic interplay between thermal and mechanical structures is modeled. One of the best illustration is the downdip limit of the interplate plane regulated by plate kinematics (controlling the convergence velocity), rheology, and mantle wedge hydration. It affects in turn the subduction equilibrium evolution through the friction force. In the vast majority of subduction models, this feedback is not simulated because the geometry of the interplate contact is fixed.

[45] Our simulations may confirm the conclusion derived from the statistical analysis of back-arcarc strain by Lallemand et al. [2008], suggesting that the arc tectonic regime is basically driven neither by the convergence rate nor by the upper plate velocity alone, but results from their combination. Moreover, our results could have implications regarding the choice of the reference frame used to determine major plate velocities. Statistical analysis of subduction kinematics are biased by the choice of the reference frame, implying assumptions on deep mantle flows [Enns et al., 2005]. In the modeling setup, plate velocities are defined with respect to the simulation box, which would 
refer in nature to a deep passive mantle, flowing only in response to plate motion. Let us considerer the simulation S25, performed with $v_{\text {sub }}=10 \mathrm{~cm} / \mathrm{a}$ and $v_{u p}=2.5 \mathrm{~cm} / \mathrm{a}$ (Table 2). In the HS3 reference frame, this plate velocity combination mimics the Kuril subduction zone (no significant arc deformation). In our modeling this surface kinematics is classified in the neutral to slightly compressive regime $\left(F_{\text {res }}=-1 \times 10^{12} \mathrm{~N} / \mathrm{m}\right)$, whereas this simulation would be located in the extensional domain defined in both NNR and SB04 reference frames [Lallemand et al., 2008]. Indeed, the "neutral line" slope in a $\left(v_{s u b}, v_{u p}\right)$ diagram decreases from 0.5 in the HS3 reference frame to 0.3 and 0.2 in the NNR and SB04 reference frames. The use of NNR or SB04 reference frames would thus emphasize the influence of upper plate velocity on back-arc tectonic regime. Our model rather predicts that arc strain is controlled by the combination of $v_{u p}$ and $v_{s u b}$. From our results, we conclude that the HS3 reference frame is more appropriate to define the plate kinematics influence on the subduction force balance.

\section{Conclusion}

[46] We use a semi-dynamic model of subduction to investigate the subducting plate and upper plate velocity influence on back-arc strain, assuming that: The rheology is mainly either brittle or viscous; lithospheres are $100 \mathrm{~km}$ thick; subduction is restricted to the upper mantle (555 km thick).

[47] 1. For a motionless overriding lithosphere, the subduction hinge is more or less fixed. As a result, stresses in the arc-back-arc area are tensional for convergence rate $<1.4 \mathrm{~cm} / \mathrm{a}$, while higher subduction velocities implies arc compression. On long timescales, i.e., closer to natural cases, the extension-compression transition occurs at a higher convergence rate $(4 \mathrm{~cm} / \mathrm{a})$ due to the hotter structure of the arc lithosphere.

[48] 2. An upper plate retreat with respect to the trench acts as tensional force on the interplate interface. Trenchward advance of the overriding lithosphere increases compression in the arc area. However, compressive stress is likely to be buffered by the arc lithosphere yield strength, especially if arc thickening by shortening is canceled by underlying convective ablation.

[49] 3. The friction force derived from the interplate surface behavior is a first-order term in the modeled subduction force balance (as the mantle Stokes reaction), in spite of the low frictional coefficient chosen for the interplate contact. The friction force depends on subduction rate, interplate rheology, and rock hydration at the mantle wedge tip.

[50] 4. Simulations modeling the plate kinematics computed in the HS3 reference frame for, respectively, the Kuril, Sandwich, and Colombia subduction zones, mimic at first order the arc deformation mode observed in nature (no deformation, arc spreading, and arc shortening, respectively). Nevertheless, our modeling of upper plate trenchward advance simulates extremely high compressive stresses, that lead to subducting plate flattening.

[51] 5. The transition from arc extension to compression modeled as a function of surface plate velocity is shifted toward higher rates of upper plate retreat than in statistical trends. The convergence rate influence on subduction force balance is stronger than inferred from statistical kinematics data. However, the model highlights the time dependency of the back-arc strain.

[52] 6. Our results confirm that the arc tectonic regime is mainly driven by the combination of convergence rate and upper plate velocity, as suggested by statistical analysis of current subduction zones [Lallemand et al., 2008]. Simulations suggest that the use of the HS3 reference frame to define plate velocities lead to a better description of the plate kinematics influence on the back-arc stress, contrary to the NNR and SB04 reference frames promoting the effect of the upper plate velocity alone.

\section{Appendix A: Testing the Subduction Force Balance Model: Friction Force Influence}

[53] We test in this appendix the subduction model sensitivity with respect to friction, whose value is predicted by equation (8) and depicted in Figure 6b. For simulations $\mathrm{S} 1$ to $\mathrm{S} 13$, the subduction model is carried on from the slab steady state (end of step 1) on 20 time iterations (duration $<10^{5}$ years) by maintaining the same convergence rate while friction stresses are canceled (crust yield stress increase with depth, $\gamma_{c}$, divided by 10 , Table A1). Compared to the values obtained at slab steady state, the resulting force, $F_{\text {res }}^{\text {no friction }}$, is now shifted toward extensive values (Figure A1a). One may notice that the resulting force dependency in convergence rate $\left(v_{c}\right)$, is significantly reduced in the absence of friction. The influence of friction on subduction 
Table A1. Subduction Short Simulations Performed to Test the Interplate Friction ${ }^{\mathrm{a}}$

\begin{tabular}{cccccc}
\hline Simulation & $\begin{array}{c}\text { Starts From } \\
\text { Simulation }\end{array}$ & $\begin{array}{c}\text { Subduction Age } \\
\text { at Onset, Ma }\end{array}$ & $\begin{array}{c}\text { Convergence } \\
\text { Rate } v_{c}, \mathrm{~cm} / \mathrm{a}\end{array}$ & $\begin{array}{c}\text { Upper Plate } \\
\text { Velocity } v_{u p}, \mathrm{~cm} / \mathrm{a}\end{array}$ & $\begin{array}{c}\text { Subducting Plate } \\
\text { Velocity } v_{\text {sub }}, \mathrm{cm} / \mathrm{a}\end{array}$ \\
\hline S2a & S2 & 76 & 1 & 0 & 1 \\
S4a & S4 & 58 & 1.6 & 0 & 1.6 \\
S6a & S6 & 30 & 3 & 0 & 3 \\
S1a & S7 & 19 & 5 & 0 & 7 \\
S9a & S9 & 13 & 7 & 0 & 8 \\
S11a & S11 & 13 & 8 & 0 & 9 \\
S12a & S12 & 10 & 11 & 0 & 11 \\
S13a & S13 & 10 & 11 & & \\
\hline
\end{tabular}

${ }^{\mathrm{a}}$ In these experiments, the crust yield stress increase $\left(\gamma_{c}\right)$ is divided by 10 and set to 0.006 .

force balance is evaluated by comparing the resulting force simulated without friction $\left(F_{\text {res }}^{\text {no friction }}\right)$ to the resulting force obtained at slab steady state, $F_{\text {res }}^{950 \mathrm{~km}}$, once the predicted friction has been withdrawn $\left(F_{\text {res }}^{950 \mathrm{~km}}-F_{\text {friction }}^{\text {computed }}\right)$, by computing the total friction force with equation (8) (Figure A1a). $\Delta F$ quantifies the difference between these two values as a function of $v_{c}$ (Figure A1b):

$$
\Delta F=F_{\text {res }}^{\text {no friction }}-\left(F_{\text {res }}^{950 \mathrm{~km}}-F_{\text {friction }}^{\text {computed }}\right)
$$

For $1.6 \leq v_{c} \leq 9 \mathrm{~cm} / \mathrm{a}, \Delta F$ is low and roughly constant with convergence rate $\left(\sim 1.7 \times 10^{12} \mathrm{~N} / \mathrm{m}\right)$, suggesting that our friction prediction is correct. $\Delta F>0$ is equivalent to $F_{\text {res }}^{950 \mathrm{~km}}-F_{\text {res }}^{\text {no friction }}<F_{\text {friction }}^{\text {computed }}<0$ : When friction is canceled, an extra compressive terms (equal to $\Delta F$ ), not directly related to frictional stresses, appears compared to the simulation including friction. This occurs if $v_{c} \geq 1.6 \mathrm{~cm} / \mathrm{a}$. On the contrary, $\Delta F<0$ indicates that a compressive terms, different from friction, has disappeared in the
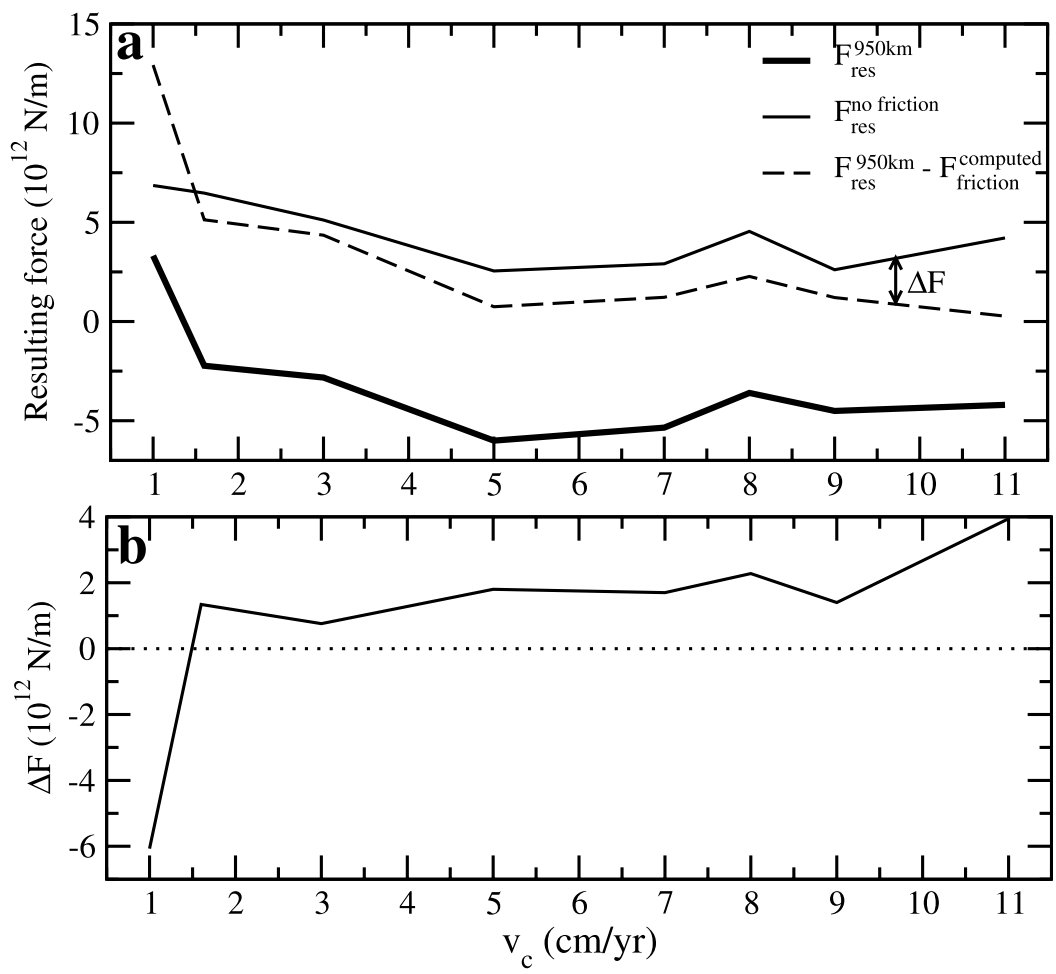

Figure A1. (a) Comparison between the resulting force obtained at $\sim 950 \mathrm{~km}$ of subducted slab length, $F_{\text {res }}^{950 \mathrm{~km}}$ (thick line), and the instantaneous resulting force when the interplate friction is suddenly set to zero $\left(F_{\text {res }}^{\text {no friction }}\right.$, thin line). The dashed line represents the difference between the resulting force, $F_{r e s}^{950 \mathrm{~km}}$, and the computed friction depicted in Figure 6a and can thus be compared to $F_{\text {res }}^{\text {no friction }}$. (b) Finally, $\Delta F$ is the difference between expected and effective contributions of friction to the total subduction force balance (see the text for explanation). 

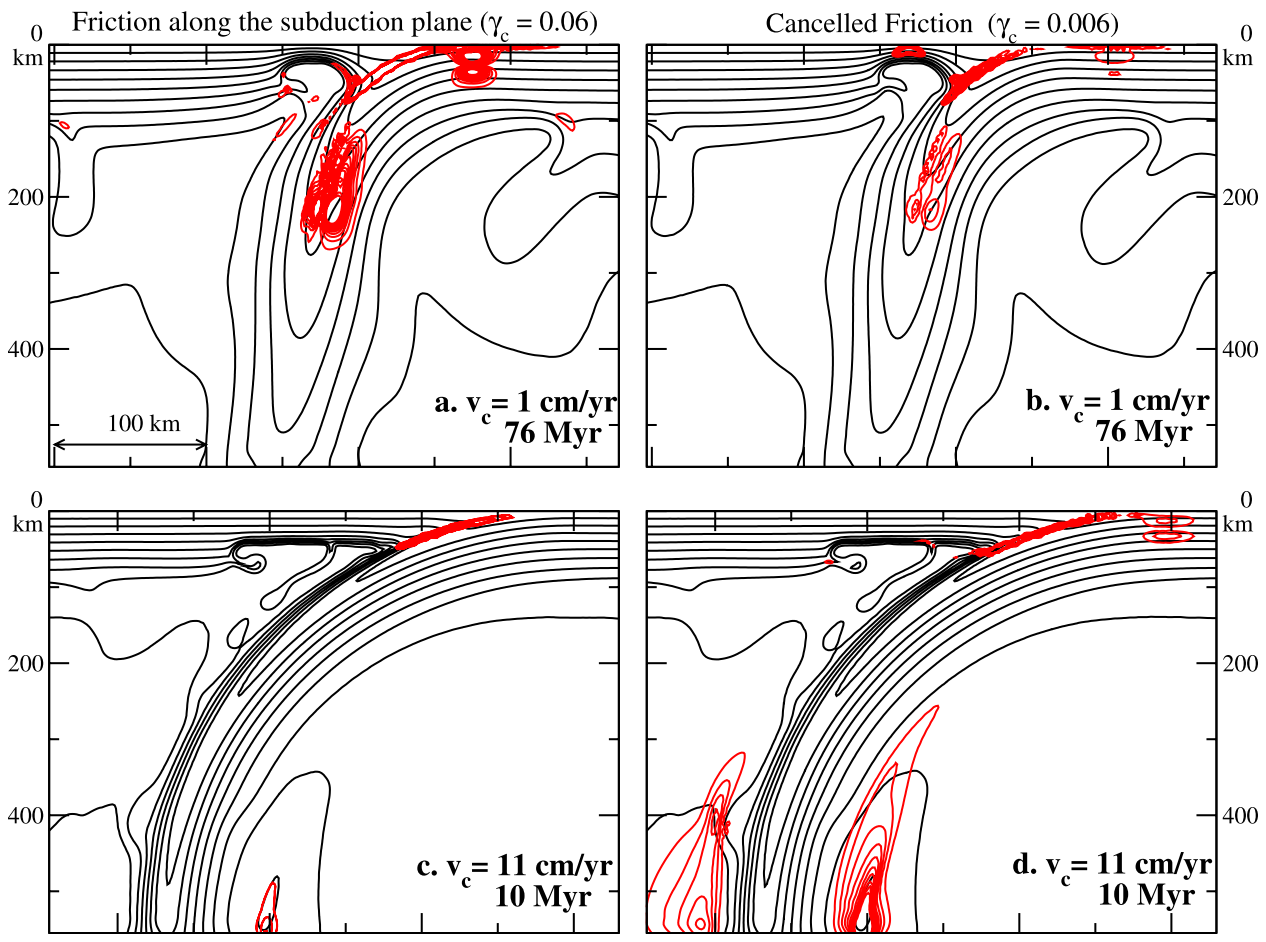

Figure A2. Thermal and mechanical states of the subduction zone when frictional forces are included in the model (Figures A2a and A2c) or canceled (Figures A2b and A2d) for a convergence rate of $1 \mathrm{~cm} / \mathrm{a}$ (Figures A2a and A2b) and $11 \mathrm{~cm} / \mathrm{a}$ (Figures A2c and A2d). Isotherms (black lines) are displayed every $150^{\circ} \mathrm{C}$. Red lines are outlines of constant energy dissipation rate (one every $0.6 \mu \mathrm{W} \cdot \mathrm{m}^{-3}$ ).

subduction model without friction $\left(v_{c}=1 \mathrm{~cm} / \mathrm{a}\right.$ simulation). To understand the origin of this excess/ lack in compressive stress, we present in Figure A2 the distribution of energy dissipation rates across the subduction zone, when friction is simulated or not. Without friction, forces resisting to subduction are the surrounding mantle strength, the arc lithosphere strength, and the subducting slab strength. For $v_{c}=11 \mathrm{~cm} / \mathrm{a}$, the dissipation rate is increased in the absence of friction both at the incoming lithosphere outer bulge and along the subducting slab surfaces at great depth: The dissipation rate rising results from the increase in subduction rate, yielding an increase of $F_{\text {Stokes }}$ compared to the simulation including friction (compare Figure A2c and Figure A2d). For $v_{c}=1 \mathrm{~cm} / \mathrm{a}$, the absence of high shear heating along the slab surfaces at great depth, as well as the dissipation rate decrease in the area where the lithosphere bends, indicate that the subduction rate tends to decrease without friction (Figures A2a and A2b). This is also suggested by the strong reduction in slab stretching rate. On the contrary, shear heating strongly increases in the arc lithosphere and along the subduction plane. By canceling frictional stress, the resulting force reaches the tensional threshold at which the arc lithosphere and the subduction plane fail: Arc spreading initiates, while the two planes of the interplate layer separate. The lithosphere subduction ceases, as the slab falls in the deep mantle.

\section{Appendix B: Influence of Subducting Slab Structure at Upper Plate Motion Onset}

[54] We test in this appendix the influence of the starting slab thermal structure when the upper plate migration is modeled (step 2 experiment). We compare simulations performed with the same kinematic boundary conditions, but differing by their starting structures. Simulations S24 and S26 (Table 2) are initiated, respectively, from simulation $\mathrm{S} 9\left(v_{c}=7 \mathrm{~cm} / \mathrm{a}\right)$ and simulation $\mathrm{S} 11\left(v_{c}=8 \mathrm{~cm} /\right.$ a) (Table 2). Simulations S24 and S26 both show the same arc strain regime $\left(v_{d}=0\right.$ and $F_{\text {res }}=$ $\left.-1.6 \times 10^{12} \mathrm{~N} / \mathrm{m}\right)$. Similarly, simulations S27 and S28 (same kinematic boundary conditions) differ by the starting subduction structures (computed respectively with $v_{c}$ equal to 9 and $11 \mathrm{~cm} / \mathrm{a}$ ) and lead to the same arc deformation and stress regime $\left(v_{d}=0\right.$ and $F_{r e s}=-5.7 \times 10^{12} \mathrm{~N} / \mathrm{m}$, Figure 14a). 
Table A2. Sensitivity of the Resulting Force, $F_{r e s}$, in Rheological Parameters: Results of Instantaneous Simulations for a Motionless Upper Plate

\begin{tabular}{|c|c|c|c|c|c|c|c|}
\hline Simulation & $\begin{array}{l}\text { Reference } \\
\text { in } F_{r e s} \text { a }\end{array}$ & $\begin{array}{c}F_{r e s}{ }^{\mathrm{a}} \text { for } \\
\gamma_{c}=0.01 \\
(-83 \%)\end{array}$ & $\begin{array}{l}F_{\text {res }}{ }^{\mathrm{a}} \text { for } \\
\gamma_{m}=0.82 \\
(-45 \%)\end{array}$ & $\begin{array}{c}F_{\text {res }}{ }^{\mathrm{a}} \text { for } \\
E_{a}{ }^{m}=380 \mathrm{~kJ} / \mathrm{mol} \\
(-3.8 \%)\end{array}$ & $\begin{array}{c}F_{\text {res }}{ }^{\mathrm{a}} \text { for } \\
E_{a}{ }^{c}=350 \mathrm{~kJ} / \mathrm{mol} \\
(+23 \%)\end{array}$ & $\begin{array}{c}F_{r e s}{ }^{\mathrm{a}} \text { for } \\
V_{a}=2.7 \times 10^{-5} \\
\mathrm{~m}^{3} / \mathrm{mol}(+45 \%)\end{array}$ & $\begin{array}{l}F_{r e s}^{\mathrm{a}} \text { for } \\
A_{0} \times 2 \\
(+100 \%)\end{array}$ \\
\hline $\begin{array}{l}\mathrm{S} 1, \\
19 \mathrm{Ma}\end{array}$ & -7.7 & $\begin{array}{c}+1.84 \\
(-124 \%)^{b}\end{array}$ & $\begin{array}{c}-4.8 \\
(-37 \%)\end{array}$ & $\begin{array}{c}-6.0 \\
(-22 \%)\end{array}$ & $\begin{array}{c}-7.8 \\
(+1 \%)\end{array}$ & $\begin{array}{c}-8.2 \\
(+7 \%)\end{array}$ & $\begin{array}{c}-9.5 \\
(+23.4 \%)\end{array}$ \\
\hline $\begin{array}{l}v_{s u b}=5 \\
\mathrm{~S} 6 \mathrm{~b}, \\
25 \mathrm{Ma}, \\
v_{s u b}=4\end{array}$ & -4.4 & $\begin{array}{c}+4.0 \\
(-192 \%)\end{array}$ & $\begin{array}{c}-1.95 \\
(-55 \%)\end{array}$ & $\begin{array}{c}-3.5 \\
(-19 \%)\end{array}$ & $\begin{array}{c}-5.3 \\
(+21 \%)\end{array}$ & $\begin{array}{c}-6.5 \\
(+49 \%)\end{array}$ & $\begin{array}{c}-6.3 \\
(+44 \%)\end{array}$ \\
\hline $\begin{array}{l}\text { S1, } \\
34 \mathrm{Ma}\end{array}$ & -4.3 & $\begin{array}{c}+2.1 \\
(-148 \%)\end{array}$ & $\begin{array}{c}-2.7 \\
(-37 \%)\end{array}$ & $\begin{array}{c}-4.1 \\
(-5 \%)\end{array}$ & $\begin{array}{c}-4.8 \\
(+10 \%)\end{array}$ & $\begin{array}{c}-5.1 \\
(+18 \%)\end{array}$ & $\begin{array}{c}-4.82 \\
(+11 \%)\end{array}$ \\
\hline $\begin{array}{l}\text { S6b, } \\
34 \mathrm{Ma}\end{array}$ & -1.8 & $\begin{array}{c}+2.4 \\
(-24 \%)\end{array}$ & $\begin{array}{c}+0.04 \\
(-102 \%)\end{array}$ & $\begin{array}{c}+1.3 \\
(-24 \%)\end{array}$ & $\begin{array}{c}-2.6 \\
(+47 \%)\end{array}$ & $\begin{array}{c}-3.6 \\
(+101 \%)\end{array}$ & $\begin{array}{c}-3.7 \\
(+52 \%)\end{array}$ \\
\hline
\end{tabular}

${ }^{\mathrm{a}} F_{\text {res }}$ values are given in $10^{12} \mathrm{~N} / \mathrm{m}$.

Therefore, a slight change in the convergence rate $( \pm 1 \mathrm{~cm} / \mathrm{a})$ used to compute the initial slab thermal state at upper plate migration initiation does not significantly affect the final state of the subduction zone, because the subducting lithosphere equilibrates through time according to the subduction rate.

\section{Appendix C: Resulting Force Dependence on Rheological Parameters}

[55] We test in this appendix the sensitivity of the resulting force in rheological parameters. The comparison between the modeled stress and the observed one in the arc area as a function of surface kinematics shows that the subduction model simulates on average a higher compression degree than in nature (Figure 14 and section 6.2). However, the mantle viscous rheology modeled in anhydrous conditions at shallow depths appears rather weak, as it is close to the wet dunite rheology [Chopra and Paterson, 1984, section 2.3]. This paradox might come from (1) the chosen low asthenosphere temperature (only $1200^{\circ} \mathrm{C}$ at $100 \mathrm{~km}$ depth, see Figure 4 for illustration) and (2) the high mantle viscosity increase with depth included here, while it is implicitly assumed to be negligible in laboratory experiments of Chopra and Paterson [1984]. Both effects favor a high strength of the simulated deep mantle. The resulting force dependence in rheological parameters is tested by performing instantaneous simulations, for two subduction simulations (one showing an arc lithosphere always under compression, the other evolving through time from compression to subneutral regime) and at two different stages. Simulations S1 and S6b $\left(v_{u p}=0, v_{s u b}=5\right.$ and $4 \mathrm{~cm} / \mathrm{a}$, respectively, Table 2) are carried on from either the subduction state at $950 \mathrm{~km}$ of convergence, or from the subduction structure obtained $34 \mathrm{Ma}$ after subduction initiation, on 20 time iterations (total duration of $\sim 10^{5}$ years) by varying one parameter after the other. We test the main six thermomechanical parameters of the model (Table A2): Frictional coefficients (crust and mantle), activation energies (crust and mantle), activation volume, and preexponential constant in Arrhenius law (equation (4)). To order the parameter respective influences, we indicate the percentage in the parameter variation and the associated variation in $F_{\text {res }}$. Note that relative variations in the resulting force are computed with respect to compression (a negative percentage indicates a compression decrease). The results show that, first, the resulting force sensitivity to a given parameter is not identical at all times and slightly differs for the two investigated convergence rates. Globally, the resulting force mainly depends on (1) the mantle activation volume $\left(E_{a}^{m}\right)$, (2) the activation volume $\left(V_{a}\right)$, and (3) the crust frictional coefficient $\left(\gamma_{c}\right)$. The mantle activation energy (1) controls the strength of the viscous bottom part within the lithosphere at the surface (viscosity increase with temperature decrease) as well as the subducting slab weakening caused by the temperature rising at great depth: $E_{a}^{m}$ partly controls the subducting slab strength. The activation volume (2) governs the mantle strength increase with depth, i.e., the deep mantle Stokes reaction competing against the slab pull. At last, the friction force (first-order term in the modeled force balance) is proportional to the crust frictional coefficient (3) (equation (8)), which explains its 
strong influence on the resulting force. To a lesser extent, the resulting force slightly depends on the mantle frictional coefficient. The crust activation energy and the preexponential constant in the viscosity law have no significant influence on the subduction force balance.

\section{Acknowledgments}

[56] We thank Anne Delplanque for her useful help in improving Figure 14. This work was partly supported by the French national program DyETI 2004-2006, "Dynamique de la subduction." We thank Harro Schmeling, an anonymous reviewer, and Peter van Keken for their constructive comments, which significantly helped to improve the manuscript.

\section{References}

Arcay, D., E. Tric, and M.-P. Doin (2005), Numerical simulations of subduction zones: Effect of slab dehydration on the mantle wedge dynamics, Phys. Earth Planet. Inter., 149, $133-153$.

Arcay, D., M.-P. Doin, E. Tric, R. Bousquet, and C. de Capitani (2006), Overriding plate thinning in subduction zones: Localized convection induced by slab dehydration, Geochem. Geophys. Geosyst., 7, Q02007, doi:10.1029/ 2005GC001061.

Arcay, D., M.-P. Doin, E. Tric, and R. Bousquet (2007a), Influence of the precollisional stage on the subduction dynamics and the burried crust thermal state: Insights from numerical simulations, Tectonophysics, 441, 27-45, doi:10.1016/j.tecto.2007.06.001.

Arcay, D., E. Tric, and M.-P. Doin (2007b), Slab surface temperature in subduction zones: Influence of the interplate decoupling depth and upper plate thinning processes, Earth Planet. Sci. Lett., 255, 324-338, doi:10.1016/ j.eps1.2006.12.027.

Asimow, P. D., J. E. Dixon, and C. H. Langmuir (2004), A hydrous melting and fractionation model for mid-ocean ridge basalts: Application to the Mid-Atlantic Ridge near the Azores, Geochem. Geophys. Geosyst., 5, Q01E16, doi:10.1029/2003GC000568.

Becker, T. W., and R. J. O'Connell (2001), Predicting plate velocities with mantle circulation models, Geochem. Geophys. Geosyst., 2(12), doi:10.1029/2001GC000171.

Becker, T., C. Faccenna, R. O'Connell, and D. Giardini (1999), The development of slabs in the upper mantle: Insights from numerical and laboratory experiments, J. Geophys. Res., 104, 15,207-15,226.

Bellahsen, N., C. Faccenna, and F. Funiciello (2005), Dynamics of subduction and plate motion in laboratory experiments: Insights into the "plate tectonics" behavior of the Earth, J. Geophys. Res., 110, B01401, doi:10.1029/ 2004JB002999.

Bercovici, D. (1996), Plate generation in a simple model of lithosphere-mantle flow with dynamic self-lubrication, Earth Planet. Sci. Lett., 144, 41-51.

Billen, M. I., and M. Gurnis (2005), Constraints on subducting plate strength within the Kermadec trench, J. Geophys. Res., 110, B05407, doi:10.1029/2004JB003308.

Billen, M. I., and G. Hirth (2007), Rheologic controls on slab dynamics, Geochem. Geophys. Geosyst., 8, Q08012, doi:10.1029/2007GC001597.
Bousquet, R., B. Goffé, P. Henry, X. Le Pichon, and C. Chopin (1997), Kinematic, thermal and petrological model of the Central Alps: Lepontine metamorphism in the upper crust and eclogitisation of the lower crust, Tectonophysics, 273, $105-127$.

Buffett, B. A. (2006), Plate force due to bending at subduction zones, J. Geophys. Res., 111, B09405, doi:10.1029/ 2006JB004295.

Buffett, B., and D. Rowley (2006), Plate bending at subduction zones: Consequences for the direction of plate motions, Earth Planet. Sci. Lett., 245, 359-364.

Byerlee, J. (1978), Friction of rocks, Pure Appl. Geophys., 116, 615-626.

Capitanio, F., G. Morra, and S. Goes (2007), Dynamic models of downgoing plate-buoyancy driven subduction: Subduction motions and energy dissipation, Earth Planet. Sci. Lett., 262, 284-297.

Carlson, R., and P. Melia (1984), Subduction hinge migration, Tectonophysics, 102, 399-411.

Carlson, R., T. Hilde, and S. Uyeda (1983), The driving mechanism for plate tectonics: Relation to age of the lithosphere at trenches, Geophys. Res. Lett., 10, 297-300.

Chase, C. (1978), Extension behind island arcs and motions relative to hot spots, J. Geophys. Res., 83, 5380-5387.

Chemenda, A., J. Burg, and M. Mauttauer (2000), Evolutionary model of the Himalaya-Tibet system: Geopoem based on new modelling, geological and geophysical data, Earth Planet. Sci. Lett., 174, 397-409.

Chopra, P., and M. Paterson (1984), The role of water in the deformation of dunite, J. Geophys. Res., 89, 7861-7876.

Christensen, U. R. (1992), An Eulerian technique for thermomechanical modeling, J. Geophys. Res., 97, 2015-2036.

Christensen, U. R. (1996), The influence of trench migration on slab penetration into the lower mantle, Earth Planet. Sci. Lett., 140, 27-39.

Conder, J. (2005), A case for hot slab surface temperatures in numerical viscous flow models of subduction zones with an improved fault zone parameterization, Phys. Earth Planet. Inter., 149, 155-164.

Conrad, C., and B. Hager (1999), Effects of plate bending and fault strength at subduction zones on plate dynamics, J. Geophys. Res., 104, 17,551-17,571.

Conrad, C., and B. Hager (2001), Mantle convection with strong subduction zones, Geophys. J. Int., 144, 271-288.

Conrad, C., and C. Lithgow-Bertolloni (2002), How mantle slabs drive plate tectonics, Science, 298, 207-209.

Currie, C. A., and R. D. Hyndman (2006), The thermal structure of subduction zone back arcs, J. Geophys. Res., 111, B08404, doi:10.1029/2005JB004024.

DeMets, C. (2001), A new estimate for present-day CocosCaribbean plate motion: Implications for slip along the Central American volcanic arc, Geophys. Res. Lett., 28, 4043-4046.

Dhuime, B., D. Bosch, J.-L. Bodinier, C. J. Garrido, O. Bruguier, S. S. Hussain, and H. Dawood (2007), Multistage evolution of the Jijal ultramafic-mafic complex (Kohistan, N Pakistan): Implications for building the roots of island arcs, Earth Planet. Sci. Lett., 261, 179-200.

Doin, M.-P., and P. Henry (2001), Subduction initiation and continental crust recycling: The roles of rheology and eclogitization, Tectonophysics, 342, 163-191.

Enns, A., T. Becker, and H. Schmeling (2005), The dynamics of subduction and trench migration for viscosity stratification, Geophys. J. Int., 160, 761-775.

Faccenna, C., A. Heuret, F. Funiciello, S. Lallemand, and T. Becker (2007), Predicting trench and plate motion from 
the dynamics of a strong slab, Earth Planet. Sci. Lett., 257, 29-36, doi:10.1016/j.epsl.2007.02.016.

Funiciello, F., C. Faccenna, D. Giardini, and K. RegenauerLieb (2003a), Dynamics of retreating slabs: 2. Insights from three-dimensional laboratory experiments, J. Geophys. Res., 108(B4), 2207, doi:10.1029/2001JB000896.

Funiciello, F., G. Morra, K. Regenauer-Lieb, and D. Giardini (2003b), Dynamics of retreating slabs: 1. Insights from twodimensional numerical experiments, J. Geophys. Res., 108(B4), 2206, doi:10.1029/2001JB000898.

Funiciello, F., C. Faccenna, and D. Giardini (2004), Role of lateral mantle flow in the evolution of subduction system: Insights from 3-D laboratory experiments, Geophys. J. Int., 157, 1393-1406.

Funiciello, F., M. Moroni, C. Piromallo, C. Faccenna, A. Cenedese, and H. A. Bui (2006), Mapping mantle flow during retreating subduction: Laboratory models analyzed by feature tracking, J. Geophys. Res., 111, B03402, doi:10.1029/2005JB003792.

Furukawa, Y. (1993), Depth of the decoupling plate interface and thermal structure under arcs, J. Geophys. Res., 98, $20,005-20,013$.

Garrido, C., J.-L. Bodinier, J.-P. Burg, G. Zeilinger, S. Hussain, H. Dawood, S. Chaudhry, and F. Gervilla (2006), Petrogenesis of mafic garnet granulite in the lower crust of the Kohistan paleo-arc complex (Northern Pakistan): Implications for intra-crustal differentiation of island arcs and generation of continental crust, J. Petrol., 47, 1873-1914, doi:10.1093/ petrology/eg1030.

Garrido, C. J., J.-L. Bodinier, B. Dhuime, D. Bosch, I. Chanefo, O. Bruguier, S. S. Hussain, H. Dawood, and J.-P. Burg (2007), Origin of the island arc Moho transition zone via melt-rock reaction and its implications for intracrustal differentiation of island arcs: Evidence from the Jijal complex (Kohistan complex, northern Pakistan), Geology, 35, 683686.

Garzione, C., P. Molnar, J. Libarkin, and B. MacFadden (2005), Rapid late Miocene rise of the Bolivian Altiplano: Evidence for removal of mantle lithosphere, Earth Planet. Sci. Lett., 241, 543-556.

Gripp, A. E., and R. G. Gordon (2002), Young tracks of hotspots and current plate velocities, Geophys. J. Int., 150, $321-361$

Hall, C., and M. Gurnis (2003), Catastrophic initiation of subduction following forced convergence across fractures zones, Earth Planet. Sci. Lett., 212, 15-30.

Hassani, R., D. Jongmans, and J. Chéry (1997), Study of plate deformation and stress in subduction processes using twodimensional numerical models, J. Geophys. Res., 102, $17,951-17,965$.

Heuret, A., and S. Lallemand (2005), Plate motions, slab dynamics and back-arc deformation, Phys. Earth Planet. Inter., $149,31-51$.

Heuret, A., F. Funiciello, C. Faccenna, and S. Lallemand (2007), Plate kinematics, slab shape and back-arc stress: A comparison between laboratory models and current subduction zones, Earth Planet. Sci. Lett., 256, 473-483, doi:10.1016/j.eps1.2007.02.016.

Hirth, G., and D. Kohlstedt (1996), Water in the oceanic upper mantle: Implications for rheology, melt extraction and the evolution of the lithosphere, Earth Planet. Sci. Lett., 144, 93-108.

Honda, S., and T. Yoshida (2005), Application of the model of small-scale convection under the island arc to the NE Honshu subduction zone, Geochem. Geophys. Geosyst., 6, Q01002, doi:10.1029/2004GC000785.
Kirby, S. (1983), Rheology of the lithosphere, Rev. Geophys., $21,1458-1487$.

Kohlstedt, D., B. Evans, and S. Mackwell (1995), Strength of the lithosphere: Constraints imposed by laboratory experiments, J. Geophys. Res., 100, 17,587-17,602.

Kohlstedt, D., H. Keppler, and D. Rubie (1996), Solubility of water in the $\alpha, \beta$ and $\gamma$ phases of $(\mathrm{Mg}, \mathrm{Fe})_{2} \mathrm{SiO}_{4}$, Contrib. Mineral. Petrol., 123, 345-357.

Lallemand, S., A. Heuret, C. Faccenna, and F. Funiciello (2008), Subduction dynamics as revealed by trench migration, Tectonics, doi:10.1029/2007TC002212, in press.

Lamb, S. (2006), Shear stresses on megathrusts: Implications for mountain building behind subduction zones, J. Geophys. Res., 111, B07401, doi:10.1029/2005JB003916.

Levitt, D., and D. Sandwell (1995), Lithospheric bending at subduction zones based on depth soundings and satellite gravity, J. Geophys. Res., 100, 379-400.

Lu, R., and H. Keppler (1997), Water solubility in pyrope to 100 kbar, Contrib. Mineral. Petrol., 129, 35-42.

McNutt, M., and H. Menard (1982), Constraints on yield strength in the oceanic lithosphere derived from observations of flexure, Geophys. J. R. Astron. Soc., 71, 363-394.

Mei, S., W. Bai, T. Hiraga, and D. Kohlstedt (2002), Influence of melt on the creep behavior of olivine-basalt aggregates under hydrous conditions, Earth Planet. Sci. Lett., 201, 491-507.

Piromallo, C., T. W. Becker, F. Funiciello, and C. Faccenna (2006), Three-dimensional instantaneous mantle flow induced by subduction, Geophys. Res. Lett., 33, L08304, doi:10.1029/2005GL025390.

Ranalli, G. (1995), Rheology of the Earth, 2nd ed., 413 pp., Chapman and Hall, London.

Ranero, C., J. Phipps Morgan, K. McIntosh, and C. Reichert (2003), Bending-related faulting and mantle serpentinization at the Middle America trench, Nature, 425, 367-373.

Rauch, M., and H. Keppler (2002), Water solubility in orthopyroxene, Contrib. Mineral. Petrol., 143, 525-536.

Regenauer-Lieb, K., and D. Yuen (1998), Rapid conversion of elastic energy into shear heating during incipient necking of the lithosphere, Geophys. Res. Lett., 25, 2737-2740.

Ribe, N. (2003), Periodic folding of viscous sheets, Phys. Rev. E, 68, 036305, doi:10.1103/PhysRevE.68.036305.

Ricard, Y. (2007), Physics of mantle convection, in Treatise on Geophysics, vol. 7, Mantle Dynamics, edited by G. Schubert and D. Bercovici, pp. 31-87, Elsevier, Amsterdam.

Richards, M., and B. Hager (1984), Geoid anomalies in a dynamic Earth, J. Geophys. Res., 89, 5987-6002.

Schellart, W. (2005), Influence of the subducting pate velocity on the geometry of the slab and migration of the subduction hinge, Earth Planet. Sci. Lett., 231, 197-219.

Schmeling, H., R. Monz, and D. Rubie (1999), The influence of olivine metastability on the dynamics of subduction, Earth Planet. Sci. Lett., 165, 55-66.

Schmidt, M., and S. Poli (1998), Experimentally based water budgets for dehydrating slabs and consequences for arc magma generation, Earth Planet. Sci. Lett., 163, 361-379.

Scholz, C., and J. Campos (1995), On the mechanism of seismic decoupling and the back arc spreading at subduction zones, J. Geophys. Res., 100, 22,105-22,115.

Shemenda, A. (1994), Subduction: Insights From Physical Modeling, Kluwer Acad., Dordrecht, Netherlands.

Stegman, D. R., J. Freeman, W. P. Schellart, L. Moresi, and D. May (2006), Influence of trench width on subduction hinge retreat rates in 3-D models of slab rollback, Geochem. Geophys. Geosyst., 7, Q03012, doi:10.1029/ $2005 \mathrm{GC} 001056$. 
Steinberger, B., R. Sutherland, and R. O'Connell (2004), Prediction of Emperor-Hawaii seamount locations from a revised model of global motion and mantle flow, Nature, 430, $167-173$.

Tackley, P. J. (2000), Self-consistent generation of tectonic plates in time-dependent, three-dimensional mantle convection simulations, Geochem. Geophys. Geosyst., 1(8), doi:10.1029/2000GC000043.

Turcotte, D., and G. Schubert (1982), Geodynamics: Applications of Continuum Physics to Geological Problems, John Wiley, New York.

Uyeda, S., and H. Kanamori (1979), Back-arc opening and the mode of subduction zones, J. Geophys. Res., 84, 10491062.

van Keken, P., S. King, H. Schmeling, U. Christensen, D. Neumeister, and M.-P. Doin (1997), A comparison of methods for the modeling of thermochemical convection, J. Geophys. Res., 102, 22,477-22,495.

von Herzen, R., C. Ruppel, P. Molnar, M. Nettles, S. Nagihara, and G. Ekström (2001), A constraint in the shear stress at the Pacific-Australian plate boundary from heat flow and seismicity at the Kermadec forearc, J. Geophys. Res., 106, 6817-6833.

Wang, K., and J. He (1999), Mechanics of low-stress forearcs: Nankai and Cascadia?, J. Geophys. Res., 104, 15,19115,205 .

Wang, K., and K. Suyehiro (1999), How does plate coupling affect crustal stresses in northeast and southwest Japan?, Geophys. Res. Lett., 26, 2307-2310. 